\title{
Statistical APPROACH TO THE ANALYSIS OF the Cut Quality in Laser Cutting Process
}

\author{
Gotlih, J.; KlancniK, S.; Begic-HajdareVic, D.; Ficko, M.; \\ CEKIC, A.; BALIC, J. \& COHODAR, M.
}

Abstract: The laser cutting process is a popular technology for cutting different types of materials economically. Kerf width and surface roughness are affected by laser power, cutting speed and type of assist gas. In this paper $\mathrm{CO}_{2}$ laser cutting of tungsten alloy is investigated. Statistical approach is used to analysis the impact of the process parameters on the quality characteristics. The analysis shows that the quality of the cut depends on all considered process parameters and that it is affected differently at different assist gases. Cutting speed has a stronger effect on the kerf width when used air as assist gas, while for oxygen and nitrogen the laser power has a stronger effect. Laser power has a stronger effect on surface roughness when used air and oxygen as assist gasses, while cutting speed has a stronger effect if nitrogen is used.

Key words: $\mathrm{CO}_{2}$ laser cutting, tungsten alloy, cut quality, statistical approach
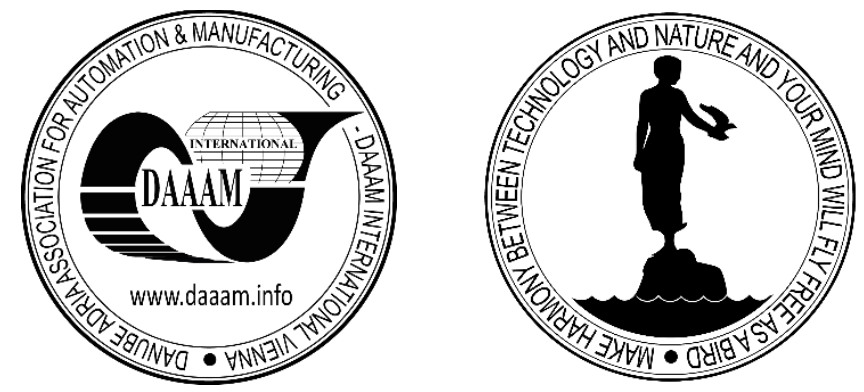

Authors' data: Gotlih, J[anez]*; Assist.Prof. Klancnik, S[imon]*; Assoc.Prof. Begic-Hajdarević, D[erzija]**; Assoc.Prof. Ficko, M[irko]*; Assoc.Prof. Cekic, A[hmet]**; Full Prof. Balic, J[oze $]^{*}$; Full Prof. Cohodar, M[aida $]^{* *}$, Univ. of Maribor, Faculty of Mech. Eng., **Univ. of Sarajevo, Faculty of Mech. Eng., janez.gotlih@um.si,simon.klancnik@um.si,begic@mef.unsa.ba,mirko.ficko@um.si, cekic@mef.unsa.ba, joze.balic@um.si,cohodar@mef.unsa.ba

This Publication has to be referred as: Gotlih, J[anez]; Klancnik, S[imon]; BegicHajdarevic, D[erzija]; Ficko, M[irko]; Cekic, A[hmet]; Balic, J[oze] \& Cohodar, M[aida] (2017). Statistical Approach to the Analysis of the Cut Quality in Laser Cutting Process, Chapter 01 in DAAAM International Scientific Book 2017, pp.001018, B. Katalinic (Ed.), Published by DAAAM International, ISBN 978-3-902734-129, ISSN 1726-9687, Vienna, Austria DOI: $10.2507 /$ daaam.scibook.2017.01 
Gotlih, J.; Klancnik, S.; Begic-Hajdarevic, D.; Ficko, M.; Cekic, A.; Balic, J. \& Co...

\section{Introduction}

Laser beam machining is an advanced non-traditional thermal process, and it has a wide range of applications in different machining processes in industry due to its advantages. The laser beam cutting process has a several advantages in comparison with other cutting process such as: process can be carried out under atmospheric conditions, there is no mechanical contact between work piece and laser device, a small heat-affected zone and narrow kerf, various type of materials can be cut, it has high degree of flexibility (Eltawahni et al., 2016). The focus of manufacturers using laser cutting process is the optimization of the productivity and the required quality of the products made by laser cutting. Both aspects are dependent on the appropriate choice of the process parameters, and these parameters are different for each type of material and thickness. These parameters are usually laser power, cutting speed, focus position, and assist gas pressure and type. The effect of process parameters in $\mathrm{CO}_{2}$ laser cutting of stainless steel of medical grade AISI316L using nitrogen as an assist gas are analysed (Eltawahni et al., 2012). Authors shown that the upper kerf width increases as the laser power, pressure of nitrogen and diameter of nozzle increase, but it decreases by increasing of cutting speed and focus position. Assist gas type is essential to minimize the production cost by increasing the cutting speed. Changing the assist gas type and its effect on the pulsed and CW Nd:YAG laser cutting of $1.2 \mathrm{~mm}$ austenitic stainless steel sheets is studied by (Ghany \& Newishy, 2005). It is shown that in comparison nitrogen with oxygen, nitrogen caused brighter and smoother cut surface with smaller kerf, although it did not prove to be economical. A grey based response surface methodology is used to predict the optimal level of cutting parameters in $\mathrm{CO}_{2}$ laser cutting of Al6061/SiC/A12O3 composite sheets with $4 \mathrm{~mm}$ thickness (Adalarasan et al., 2015). Laser power, pulsing frequency, cutting speed and assist gas pressure are considered as cutting parameters.

For modelling and optimizing of any machining processes, the numerical methods (Begic-Hajdarevic \& Bijelonja, 2014; Kadri et al., 2015), artificial neural network (Klancnik et al., 2015; Saric et al., 2016; Mohamed et at., 2016), fuzzy logical method (Rodic et at., 2014; Saenz et al., 2015) and other intelligent techniques (Ficko \& Placic, 2013; Klancnik et al., 2016; Rao et al., 2016) are common used. Further analyses of interest are especially laser cut uncommon materials. Experimental study on the laser cutting of difficult to laser cut Duralumin sheet by using a hybrid approach which is obtained by the integration of robust parameter design with fuzzy logic theory is performed (Pandey \& Dubey, 2012). The aim was to improve geometrical accuracy by simultaneously minimizing the kerf width and kerf deviations at top and bottom sides. In order to evaluate the surface roughness of the laser cutting of tungsten alloy by using oxygen as assist gas, statistical process control method based on control charts is applied (Begic-Hajdarevic et al., 2015). Key objective was to find cutting speed and laser power achieving stable process and best cutting quality.

In this research paper a statistical approach is used to analysis the impact of the process parameters on the quality characteristics. The experiments are performed on $1 \mathrm{~mm}$ thick tungsten alloy sheet using $\mathrm{CO}_{2}$ laser system. Three input process 
parameters such as laser power, cutting speed and assist gas type are taken into account. Kerf width and surface roughness are considered as output characteristics.

\section{Experimental procedure}

The experiments are conducted on a CW $2000 \mathrm{~W}$ Rofin laser with focal length of $127 \mathrm{~mm}$. Tungsten alloy in sheet is used as work piece material. Specimens are cut on dimensions $100 \mathrm{~mm}$ x $100 \mathrm{~mm}$ with $1 \mathrm{~mm}$ thickness. Three different assist gasses such as nitrogen, air and oxygen are used in experiments. Assist gas is supplied coaxially with the laser beam through a $2 \mathrm{~mm}$ nozzle diameter. Nozzle distance, focus position and assist gas pressure are kept constant, and their values in given in Table 1.

\begin{tabular}{|l|c|c|c|}
\hline \multirow{2}{*}{ Process Parameters } & \multicolumn{3}{|c|}{ Assist Gas Type } \\
\cline { 2 - 4 } & Air & Oxygen & Nitrogen \\
\hline Nozzle distance [mm] & 1 & 1 & 0.75 \\
\hline Focus position [mm] & -1 & -0.5 & -0.5 \\
\hline Assist gas pressure [bar] & 15 & 12.5 & 15 \\
\hline
\end{tabular}

Tab. 1. Process parameters and their values.

The upper kerf width is measured using an optical microscope fitted with a video camera and a zoom lens. The average of five measurements of kerf width is recorded for all specimens. The arithmetic average roughness parameter $R a$, values are measured using a Taylor-Hobson stylus instrument. Five consistent surface roughness values of each specimen are measured and an average value is calculated for each specimen. Roughness is measured along the length of a cut surface approximately in the middle of the thickness.

\section{Measurement data analysis}

A statistical analysis is performed to evaluate the measurement data. Measurement data are given in Table 2. The analysis contains a summary of measurement data, histogram plots for each result parameter, normal plots for each result parameter, overall box plots for each result parameter and box plots for each result parameter by each process parameter. Each assist gas is considered separately.

The summary of measurement data shows experimental values for both process parameters, number of measurements available for each parameter and minimum, maximum, mean, median, first and third quartile values for both result parameters.

Histogram plot intervals include the higher value end point, but not the lower value end point, with exception of the first cell which also includes the lower value end point. In the normal Q-Q plots sample quartiles are representing measurement results and are plotted versus theoretical quartiles in a sorted order. Theoretical quartiles represent a standard normal distribution. A normal line passing through first and third quartile is added. Outliners in box plots are calculated as values bellow the first quartile minus 1.5 times interquartile range or values over the third quartile plus 1.5 times interquartile range. 
Gotlih, J.; Klancnik, S.; Begic-Hajdarevic, D.; Ficko, M.; Cekic, A.; Balic, J. \& Co...

\begin{tabular}{|c|c|c|c|c|c|c|c|c|c|}
\hline 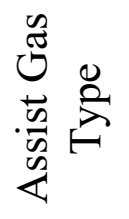 & 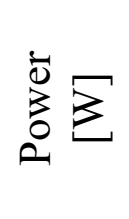 & 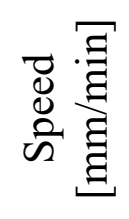 & 离志 & 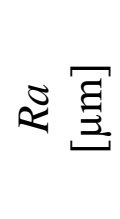 & 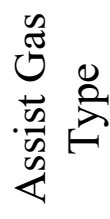 & 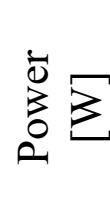 & 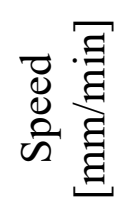 & 岕志 & $\approx \Xi$ \\
\hline Air & 1500 & 2000 & 0.24 & 5.24 & $\mathrm{O}_{2}$ & 1750 & 4500 & 0.32 & 6.25 \\
\hline Air & 1500 & 3000 & 0.22 & 4.04 & $\mathrm{O}_{2}$ & 1750 & 5000 & 0.27 & 7.13 \\
\hline Air & 1500 & 3500 & 0.23 & 2.76 & $\mathrm{O}_{2}$ & 1750 & 5500 & 0.31 & 5.97 \\
\hline Air & 1500 & 2500 & 0.23 & 3.30 & $\mathrm{O}_{2}$ & 1750 & 4000 & 0.32 & 6.80 \\
\hline Air & 1750 & 2000 & 0.24 & 5.46 & $\mathrm{O}_{2}$ & 2000 & 3000 & 0.35 & 7.73 \\
\hline Air & 1750 & 2500 & 0.23 & 3.95 & $\mathrm{O}_{2}$ & 2000 & 3500 & 0.34 & 7.22 \\
\hline Air & 1750 & 3000 & 0.23 & 3.80 & $\mathrm{O}_{2}$ & 2000 & 4000 & 0.34 & 7.18 \\
\hline Air & 1750 & 4000 & 0.23 & 3.77 & $\mathrm{O}_{2}$ & 2000 & 5000 & 0.29 & 6.01 \\
\hline Air & 1750 & 3500 & 0.22 & 3.33 & $\mathrm{O}_{2}$ & 2000 & 6000 & 0.27 & 3.73 \\
\hline Air & 2000 & 2000 & 0.24 & 7.17 & $\mathrm{O}_{2}$ & 2000 & 4500 & 0.31 & 6.14 \\
\hline Air & 2000 & 3000 & 0.23 & 4.66 & $\mathrm{O}_{2}$ & 2000 & 5500 & 0.27 & 4.49 \\
\hline Air & 2000 & 3500 & 0.23 & 4.50 & $\mathrm{~N}_{2}$ & 1500 & 1000 & 0.17 & 5.82 \\
\hline Air & 2000 & 4000 & 0.23 & 3.52 & $\mathrm{~N}_{2}$ & 1500 & 2000 & 0.19 & 4.97 \\
\hline Air & 2000 & 4500 & 0.23 & 2.77 & $\mathrm{~N}_{2}$ & 1500 & 1500 & 0.18 & 5.41 \\
\hline Air & 2000 & 2500 & 0.24 & 4.92 & $\mathrm{~N}_{2}$ & 1750 & 1000 & 0.20 & 5.33 \\
\hline $\mathrm{O}_{2}$ & 1500 & 3000 & 0.35 & 7.75 & $\mathrm{~N}_{2}$ & 1750 & 1500 & 0.19 & 5.57 \\
\hline $\mathrm{O}_{2}$ & 1500 & 3500 & 0.32 & 7.58 & $\mathrm{~N}_{2}$ & 1750 & 2000 & 0.18 & 6.56 \\
\hline $\mathrm{O}_{2}$ & 1500 & 4000 & 0.29 & 6.79 & $\mathrm{~N}_{2}$ & 2000 & 1000 & 0.20 & 5.41 \\
\hline $\mathrm{O}_{2}$ & 1500 & 4500 & 0.28 & 6.02 & $\mathrm{~N}_{2}$ & 2000 & 1500 & 0.19 & 5.92 \\
\hline $\mathrm{O}_{2}$ & 1750 & 3000 & 0.34 & 7.78 & $\mathrm{~N}_{2}$ & 2000 & 2250 & 0.19 & 7.14 \\
\hline $\mathrm{O}_{2}$ & 1750 & 3500 & 0.33 & 8.22 & $\mathrm{~N}_{2}$ & 2000 & 2000 & 0.18 & 6.23 \\
\hline
\end{tabular}

Tab. 2. Measurement data used in statistical analysis.

\subsection{Air as assist gas}

For air as assist gas is available 15 experiments. Range of cutting speed is $2000 \mathrm{~mm} / \mathrm{min}$ to $4500 \mathrm{~mm} / \mathrm{min}$ and range of laser power is $1500 \mathrm{~W}$ to $2000 \mathrm{~W}$. Number of available result points for each cutting speed and laser power is visible in Table 3. Minimum and maximum measured values for kerf width and surface roughness as well as median, mean and first and third quartile values are also visible in Table 3.

\begin{tabular}{|c|c|c|c|c|c|c|c|}
\hline \multicolumn{2}{|c|}{ Cutting Speed } & \multicolumn{2}{c|}{ Power } & \multicolumn{2}{c|}{ Kerf Width } & \multicolumn{2}{c|}{ Surface Roughness } \\
\hline$[\mathrm{mm} / \mathrm{min}]$ & $\begin{array}{c}\text { Result } \\
\text { points }\end{array}$ & {$[\mathrm{W}]$} & $\begin{array}{c}\text { Result } \\
\text { points }\end{array}$ & Value & {$[\mathrm{mm}]$} & Value & {$[\mu \mathrm{m}]$} \\
\hline 2000 & 3 & 1500 & 4 & Min. & 0.2200 & Min. & 2.760 \\
\hline 2500 & 3 & 1750 & 5 & 1st Quartile & 0.2300 & 1st Quartile & 3.425 \\
\hline 3000 & 3 & 2000 & 6 & Median & 0.2300 & Median & 3.950 \\
\hline 3500 & 3 & & & Mean & 0.2313 & Mean & 4.213 \\
\hline 4000 & 2 & & & 3rd Quartile & 0.2350 & 3rd Quartile & 4.790 \\
\hline 4500 & 1 & & & Max. & 0.2400 & Max. & 7.170 \\
\hline
\end{tabular}

Tab. 3. Summary of measurement data analysis for air. 
The measurement result frequency of kerf width (Fig. 1) is highest in range from $0.225 \mathrm{~mm}$ to $0.23 \mathrm{~mm}$ with nine available result points, four result points are available in range from $0.235 \mathrm{~mm}$ to $0.24 \mathrm{~mm}$ and two in range from $0.22 \mathrm{~mm}$ to $0.225 \mathrm{~mm}$. Zero result points are available in range from $0.23 \mathrm{~mm}$ to $0.235 \mathrm{~mm}$. The measurement result frequency of surface roughness (Fig. 1) is highest in range from $3 \mu \mathrm{m}$ to $4 \mu \mathrm{m}$ with six available result points, four result points are available in range from $4 \mu \mathrm{m}$ to $5 \mu \mathrm{m}$, two in range from $2 \mu \mathrm{m}$ to $3 \mu \mathrm{m}$ and one result point is available in range from $7 \mu \mathrm{m}$ to $8 \mu \mathrm{m}$. Zero result points are available in range from $6 \mu \mathrm{m}$ to $7 \mu \mathrm{m}$.
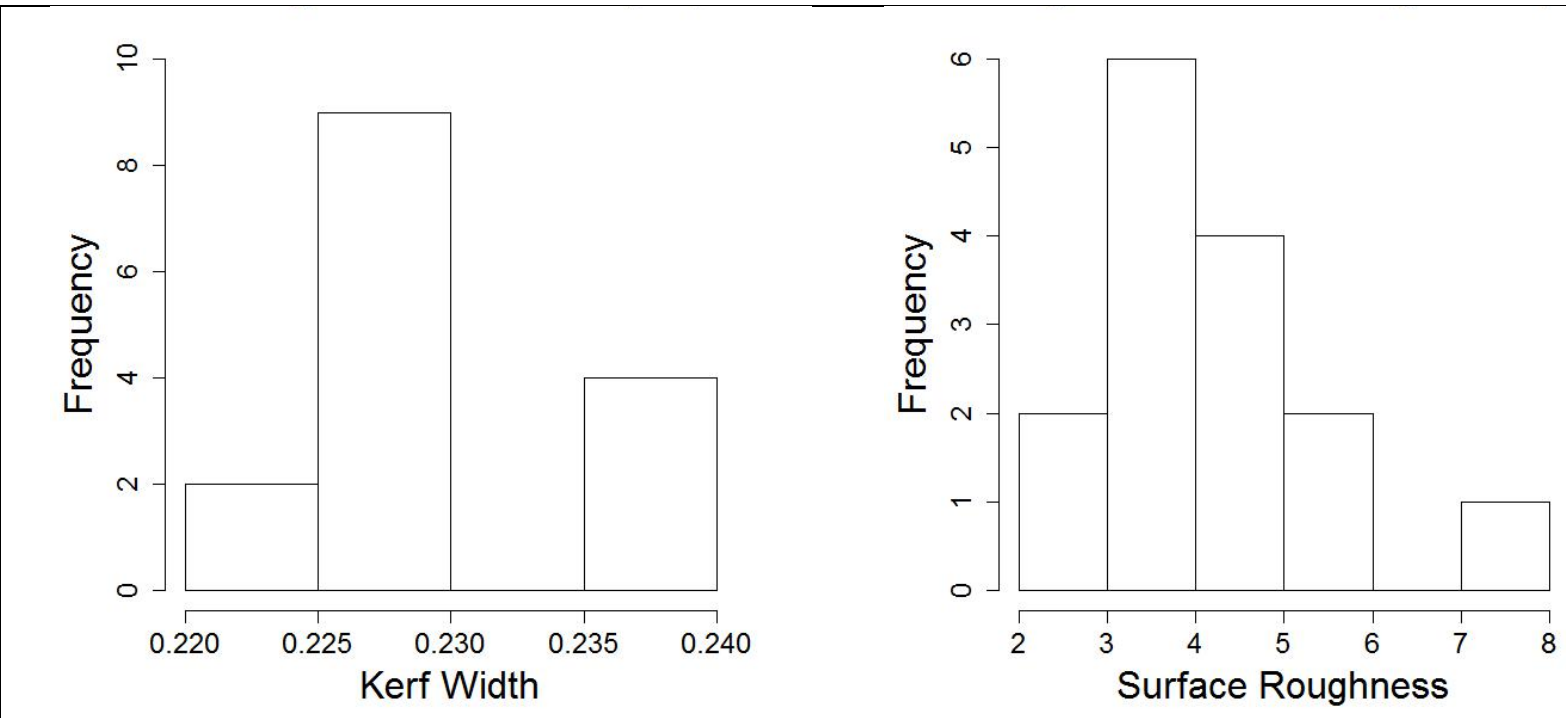

Fig. 1. Histogram for kerf width (left) and surface roughness (right) - air.

A weak match between kerf width measurement results and a normal distribution is revealed in the Q-Q normal plot graph (Fig. 2). Kerf width results are distributed on three levels. Deviations from normal line are found on all levels. A close match between surface roughness measurement results and a normal distribution is revealed in the Q-Q normal plot graph (Fig. 2). Some deviations are found at the low and the high end of the graph.
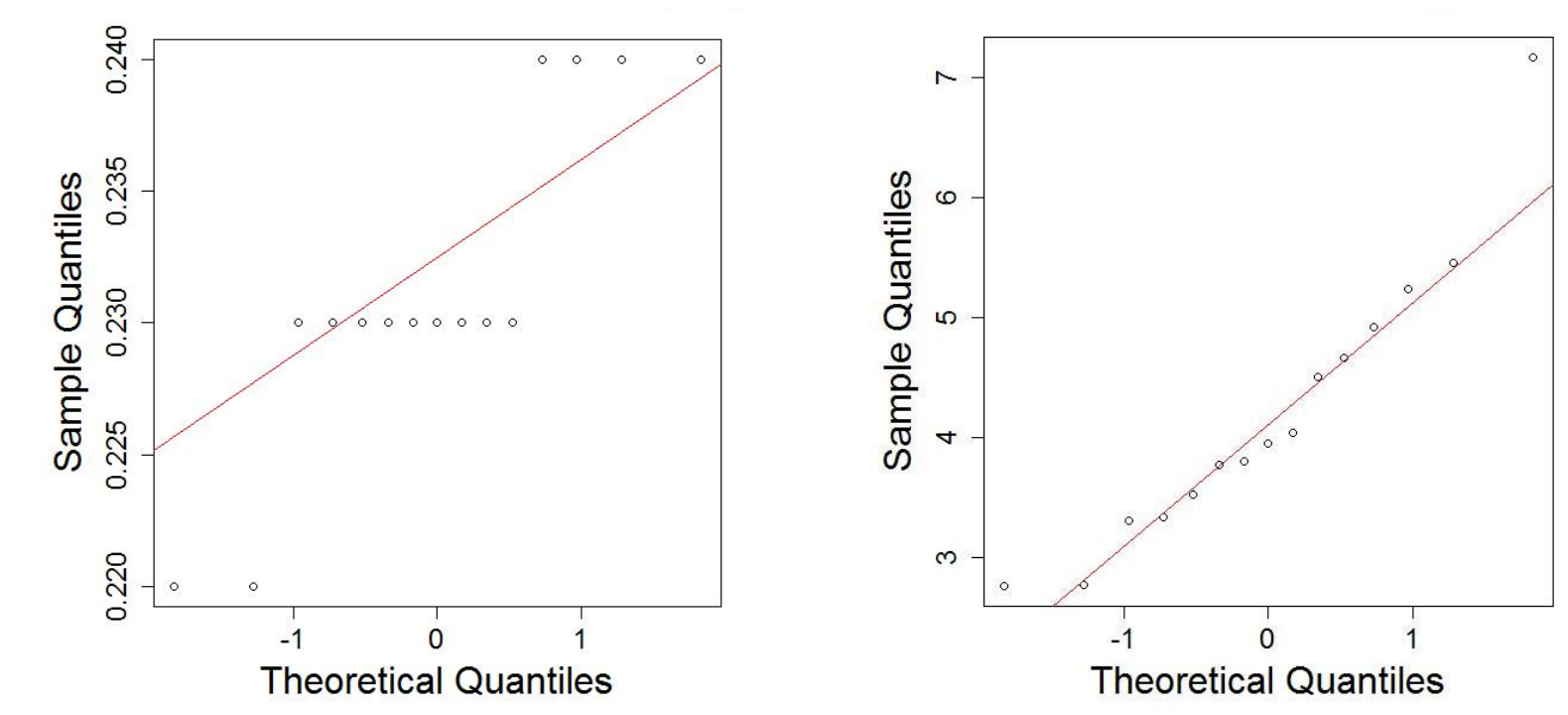

Fig. 2. Normal Q-Q plot for kerf width (left) and surface roughness (right) - air. 
Gotlih, J.; Klancnik, S.; Begic-Hajdarevic, D.; Ficko, M.; Cekic, A.; Balic, J. \& Co...

Box plot of all measured kerf width results, with a mean value of $0.23 \mathrm{~mm}$, reveals a normal result point distribution towards higher than median values and an outliner result point in lower than median direction (Fig. 3). Box plot of all measured surface roughness results, with a mean value of $4.21 \mu \mathrm{m}$, reveals a close to normal result point distribution with a wider result point distribution range towards higher than median values (Fig. 3). One outliner point is found with a measured surface roughness value of $7.17 \mu \mathrm{m}$.

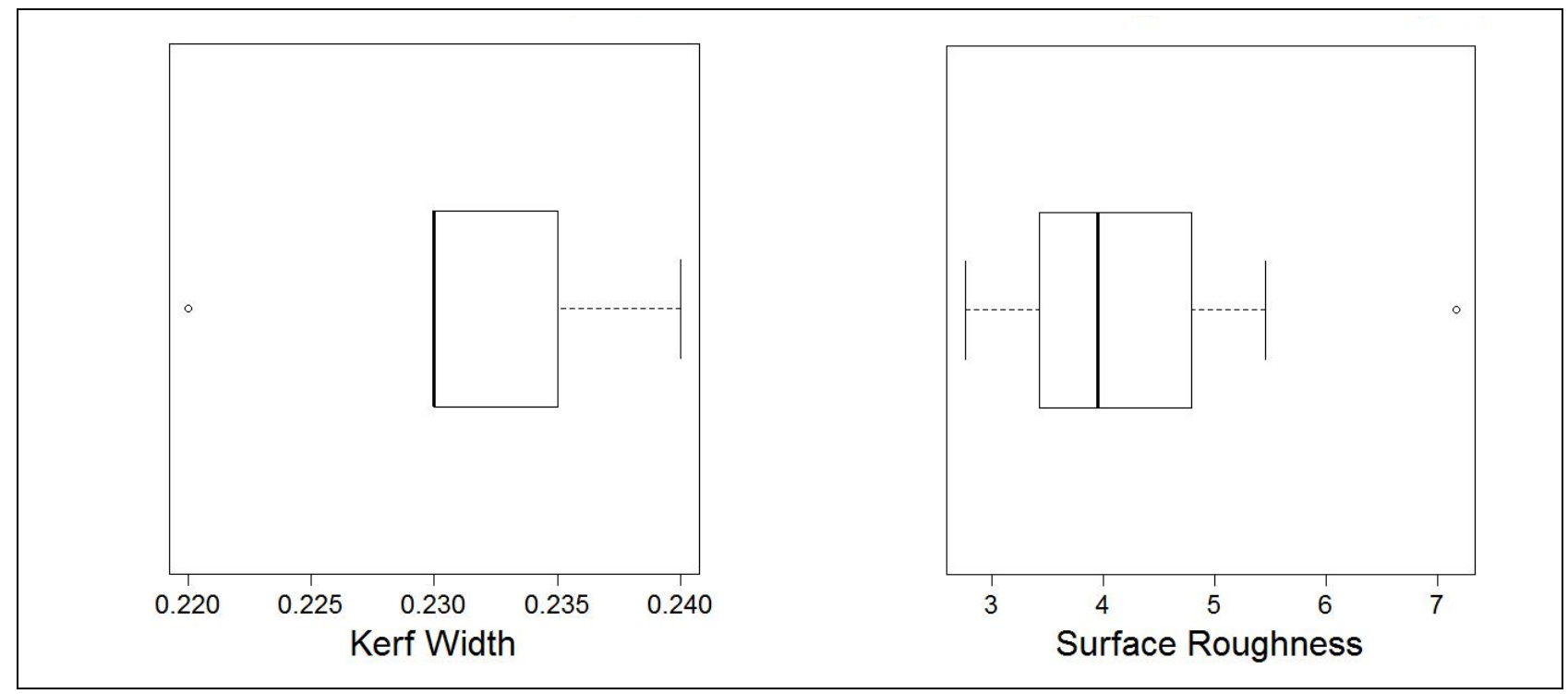

Fig. 3. Box plots of overall kerf width (left) and surface roughness (right) - air.
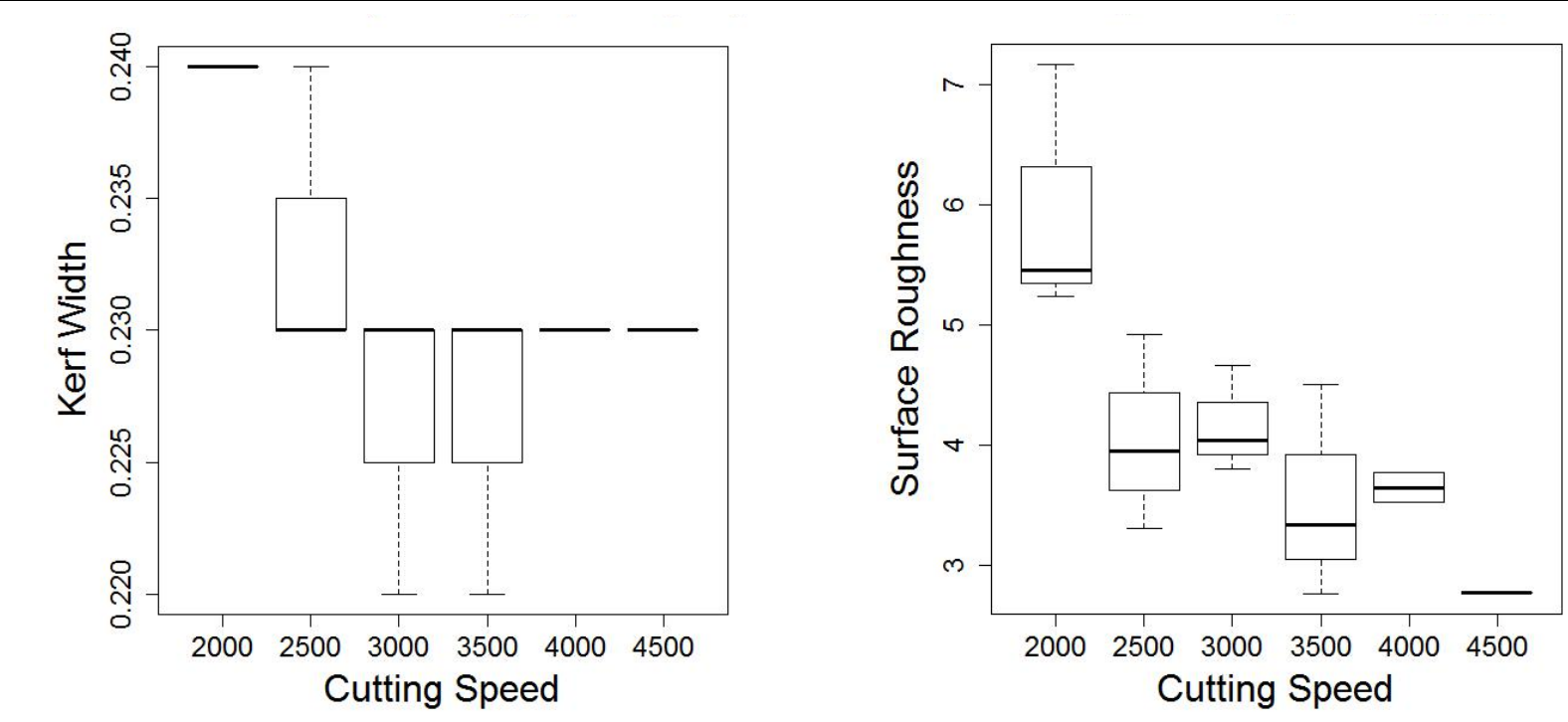

Fig. 4. Box plots for kerf width (left) and surface roughness (right) by speed - air.

Box plots of kerf width result points (Fig. 4) reveal no result point dispersion at cutting speed $2000 \mathrm{~mm} / \mathrm{min}$ with a mean at $0.24 \mathrm{~mm}$ and at $4000 \mathrm{~mm} / \mathrm{min}$ and 4500 $\mathrm{mm} / \mathrm{min}$ with a mean of $0.23 \mathrm{~mm}$. At cutting speeds 2500,3000 and $3500 \mathrm{~mm} / \mathrm{min}$ the mean kerf width value is $0.23 \mathrm{~mm}$. A one sided result point distribution with median being an edge value is revealed for those cutting speeds. At cutting speed $2500 \mathrm{~mm} / \mathrm{min}$ result points are dispersed only in the direction towards higher than median, while at 
cutting speeds $3000 \mathrm{~mm} / \mathrm{min}$ and $3500 \mathrm{~mm} / \mathrm{min}$ result points are dispersed only in the direction towards lower than median. Box plots for surface roughness (Fig. 4) reveal a close to normal result point distribution at cutting speeds $2500 \mathrm{~mm} / \mathrm{min}$ and $3500 \mathrm{~min} / \mathrm{min}$. At cutting speed $2000 \mathrm{~mm} / \mathrm{min}$ the highest result point variation is found with a wider result point distribution range towards higher than median values. A similar situation occurs at cutting speed $3000 \mathrm{~mm} / \mathrm{min}$, but with a narrower result point distribution range. At cutting speed $4000 \mathrm{~mm} / \mathrm{min}$ all result points are completely inside the first and third quartile range with a balanced distribution. At cutting speed $4500 \mathrm{~mm} / \mathrm{min}$ only one result point is available.

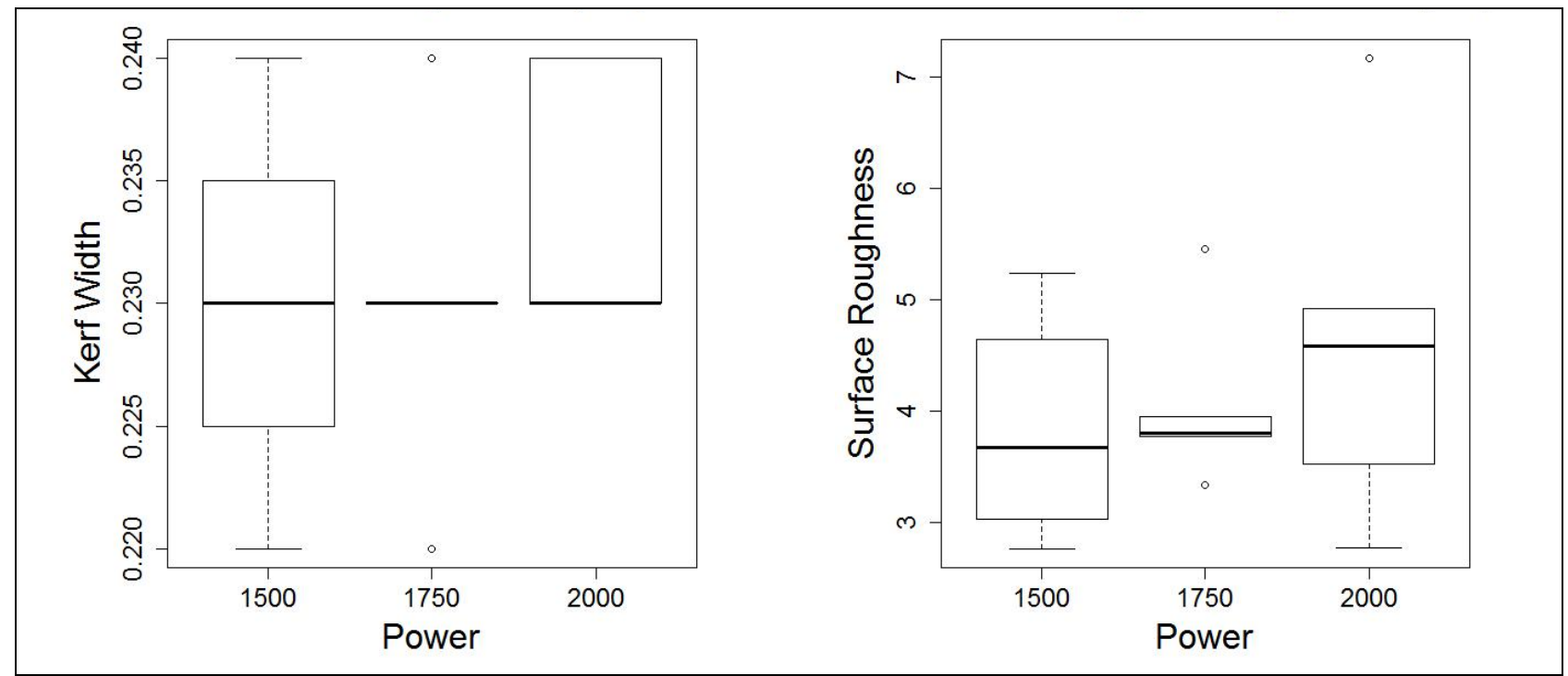

Fig. 5. Box plots for kerf width (left) and surface roughness (right) by power - air.

Box plot for kerf width (Fig. 5) at laser power $1500 \mathrm{~W}$ shows a balanced result point distribution throughout the entire kerf width range. At laser power $1750 \mathrm{~W}$ most results are measured at kerf width $0.23 \mathrm{~mm}$ with one outliner over and one bellow median. At power $2000 \mathrm{~W}$ most result points are measured at kerf width $0.23 \mathrm{~mm}$ with a couple of points at third quartile and none bellow median value. Box plot for surface roughness (Fig. 5) at laser power $1500 \mathrm{~W}$ shows a balanced result point distribution with a mean value of $3.84 \mu \mathrm{m}$, at $1750 \mathrm{~W}$ most result points are concentrated around median, with no whiskers and two outliners and a mean of $4.06 \mu \mathrm{m}$. At laser power $2000 \mathrm{~W}$ most results are concentrated around median, with a mean of $4.59 \mu \mathrm{m}$. In the direction of lower than median values result points are distributed in a wider range than in the direction of higher than median, where result points are in the median to third quartile range, with no whiskers and one outliner point.

\subsection{Oxygen as assist gas}

In statistical analysis 17 experiments are available for oxygen as assist gas. Cutting speed measurement range is $3000 \mathrm{~mm} / \mathrm{min}$ to $6000 \mathrm{~mm} / \mathrm{min}$ and laser power measurement range is $1500 \mathrm{~W}$ to $2000 \mathrm{~W}$. Number of available result points for each cutting speed and each laser power is visible in Table 4. Minimum and maximum measured values for kerf width and surface roughness as well as median, mean and first and third quartile values are also visible in Table 4. 
Gotlih, J.; Klancnik, S.; Begic-Hajdarevic, D.; Ficko, M.; Cekic, A.; Balic, J. \& Co...

\begin{tabular}{|c|c|c|c|c|c|c|c|}
\hline \multicolumn{2}{|c|}{ Cutting Speed } & \multicolumn{2}{c|}{ Power } & \multicolumn{2}{c|}{ Kerf Width } & \multicolumn{2}{c|}{ Surface Roughness } \\
\hline$[\mathrm{mm} / \mathrm{min}]$ & $\begin{array}{c}\text { Result } \\
\text { points }\end{array}$ & {$[\mathrm{W}]$} & $\begin{array}{c}\text { Result } \\
\text { points }\end{array}$ & Value & {$[\mathrm{mm}]$} & Value & {$[\mu \mathrm{m}]$} \\
\hline 3000 & 3 & 1500 & 4 & Min. & 0.2700 & Min. & 3.730 \\
\hline 3500 & 3 & 1750 & 6 & 1st Quartile & 0.2900 & 1 st Quartile & 6.020 \\
\hline 4000 & 3 & 2000 & 7 & Median & 0.3200 & Median & 6.800 \\
\hline 4500 & 3 & & & Mean & 0.3118 & Mean & 6.635 \\
\hline 5000 & 2 & & & 3rd Quartile & 0.3400 & 3rd Quartile & 7.580 \\
\hline 5500 & 2 & & & Max. & 0.3500 & Max. & 8.220 \\
\hline 6000 & 1 & & & & & & \\
\hline
\end{tabular}

Tab. 4. Summary of measurement data analysis for oxygen.

Measurement result frequency of kerf width (Fig. 6) is highest in range from $0.27 \mathrm{~mm}$ to $0.28 \mathrm{~mm}$ with four available result points. Three results points are available in range from $0.31 \mathrm{~mm}$ to $0.32 \mathrm{~mm}$ and in range from $0.33 \mathrm{~mm}$ to $0.34 \mathrm{~mm}$. Two result points are available in range from $0.28 \mathrm{~mm}$ to $0.29 \mathrm{~mm}$, from $0.3 \mathrm{~mm}$ to $0.31 \mathrm{~mm}$ and from $0.34 \mathrm{~mm}$ to $0.35 \mathrm{~mm}$. One result point is available in range from $0.32 \mathrm{~mm}$ to 0.33 $\mathrm{mm}$ and zero result points in range from $0.29 \mathrm{~mm}$ to $0.3 \mathrm{~mm}$. Measurement result frequency of surface roughness (Fig. 6) is highest in range from $7 \mu \mathrm{m}$ to $8 \mu \mathrm{m}$ with seven result available points, followed by range from $6 \mu \mathrm{m}$ to $7 \mu \mathrm{m}$ with six result points. One result point is available in each of the remaining range intervals.

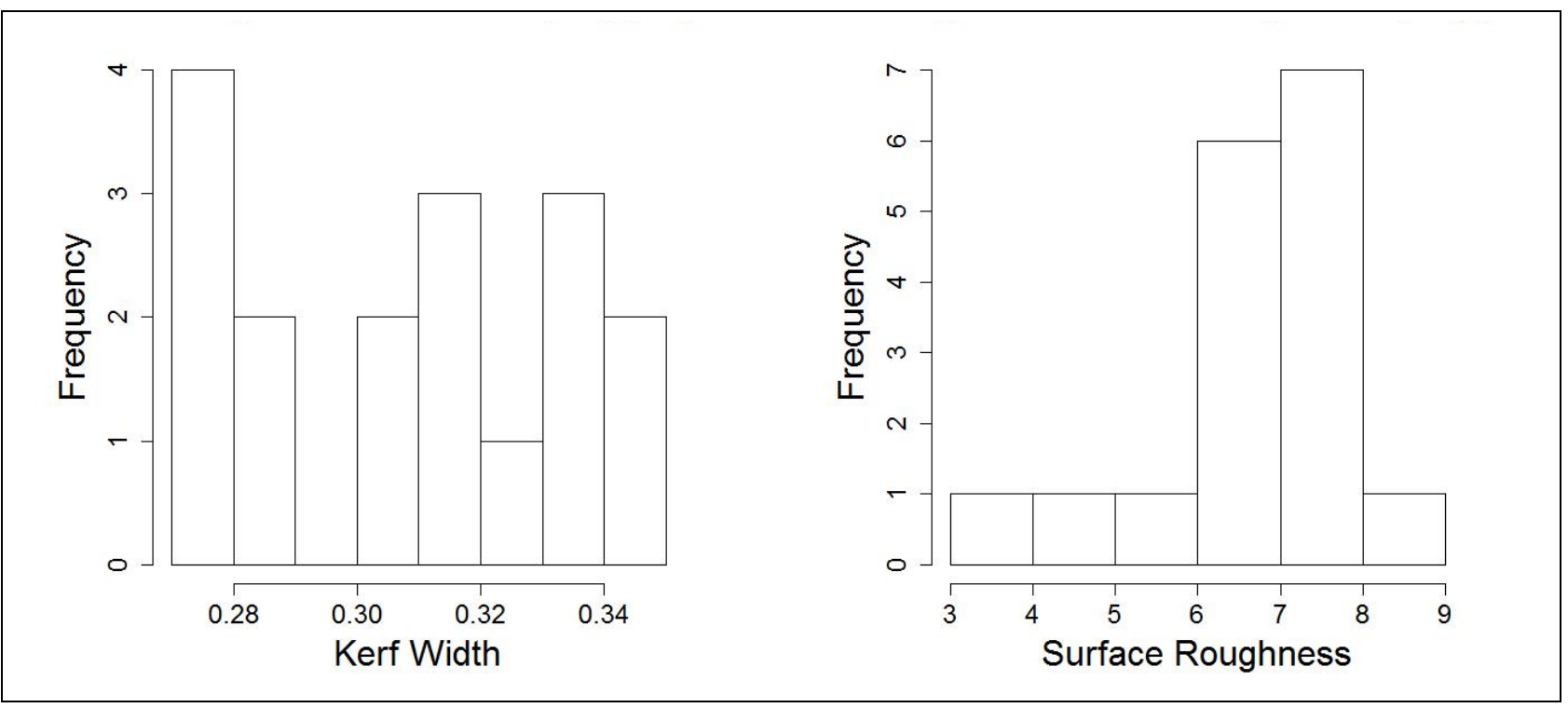

Fig. 6. Histogram for kerf width (left) and surface roughness (right) - oxygen.

A weak match between kerf width results and a normal distribution is revealed in the Q-Q normal plot graph (Fig. 7). Some major deviations from the normal line are found at the low and the high end of the graph. A weak match between surface roughness results and a normal distribution is revealed in the Q-Q normal plot graph (Fig. 7). Some major deviations are found at the low and the high end of the graph. 

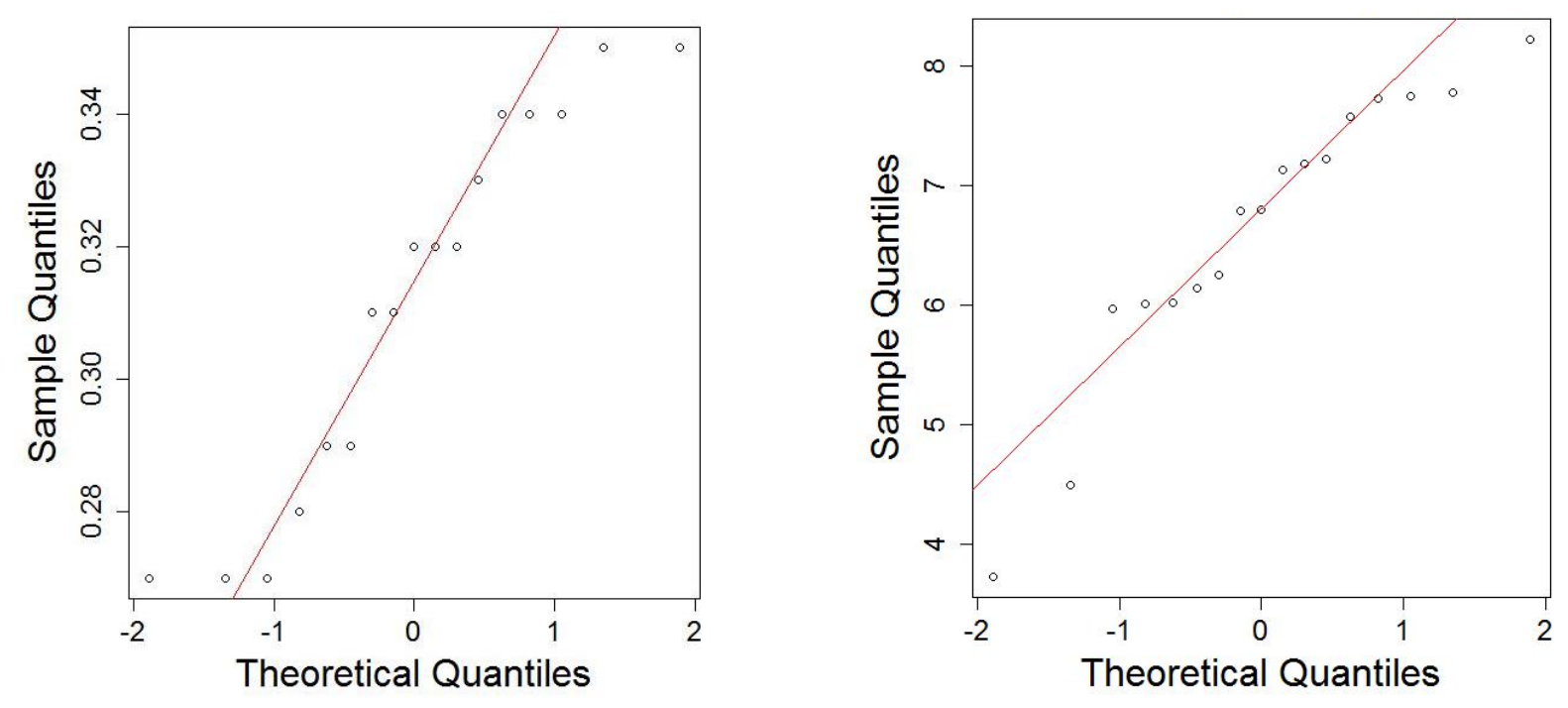

Fig. 7. Normal Q-Q plot for kerf width (left) and surface roughness (right) - oxygen.

Box plot of all measured kerf width results (Fig. 8), with a mean value of $0.31 \mathrm{~mm}$, reveals a close to normal result point distribution with a denser distribution range in the direction towards higher than median values. Box plot of all measured surface roughness results reveals a close to normal result point distribution between the first and third quartile, (Fig. 8). A wider variation range of result points is found in the smaller than first quartile whiskers interval compared to the opposite, higher than third quartile interval. The mean value of surface roughness results is $6.63 \mu \mathrm{m}$.

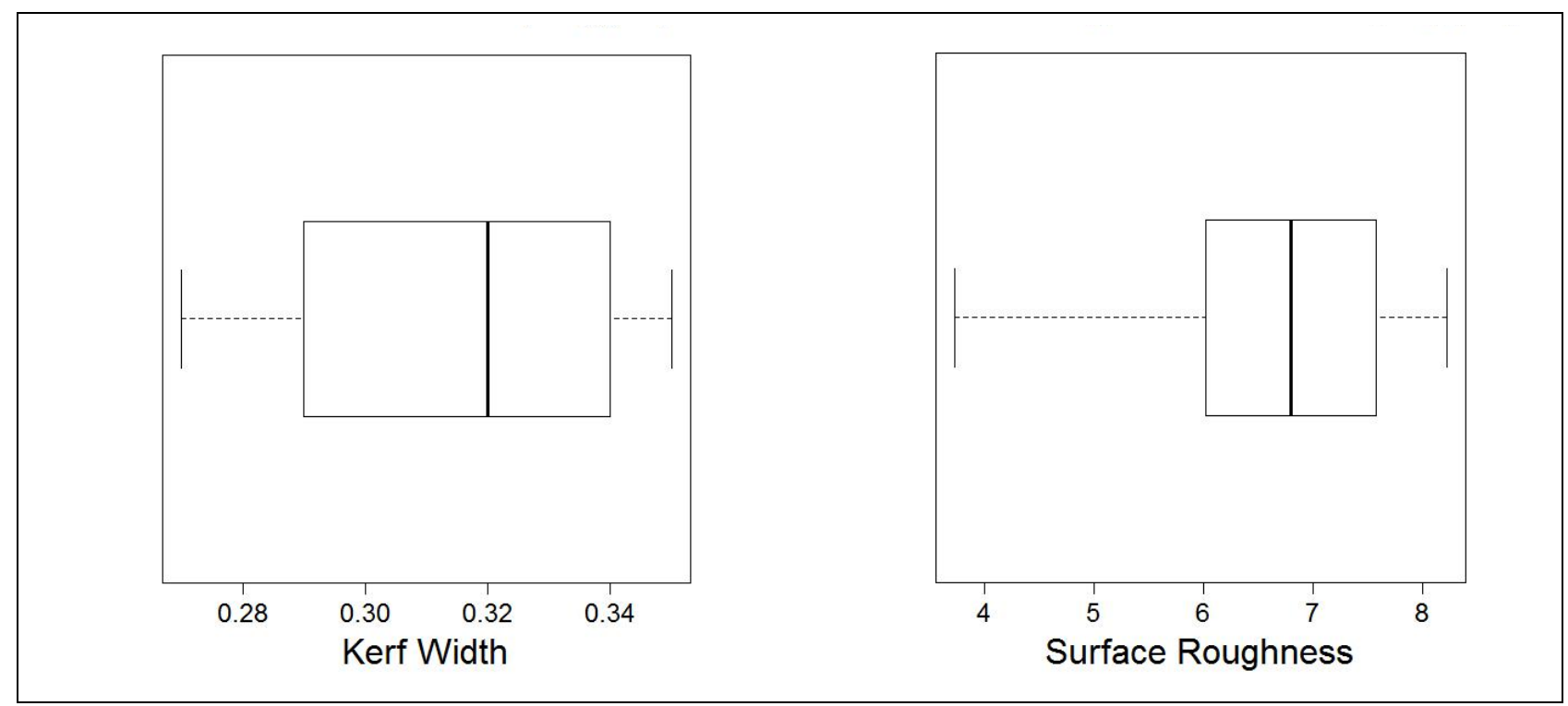

Fig. 8. Box plots of overall kerf width (left) and surface roughness (right) - oxygen.

Box plots of kerf width by cutting speed (Fig. 9) reveal a close to normal result point distribution at cutting speeds $3500 \mathrm{~mm} / \mathrm{min}, 4000 \mathrm{~mm} / \mathrm{min}$ and $4500 \mathrm{~mm} / \mathrm{min}$ with a denser result point distribution towards higher kerf width values for all three cases. At cutting speed $3000 \mathrm{~mm} / \mathrm{min}$ result points are available only in the lower than median direction, at $5000 \mathrm{~mm} / \mathrm{min}$ and $5500 \mathrm{~mm} / \mathrm{min}$ only two result points are available and at $6000 \mathrm{~mm} / \mathrm{min}$ only one result point is available. Kerf width mean value 
at cutting speed $3000 \mathrm{~mm} / \mathrm{min}$ is $0.35 \mathrm{~mm}$, at $3500 \mathrm{~mm} / \mathrm{min}$ it is $0.33 \mathrm{~mm}$, at $4000 \mathrm{~mm} / \mathrm{min}$ it is $0.32 \mathrm{~mm}$ at $4500 \mathrm{~mm} / \mathrm{min}$ it is $0.317 \mathrm{~mm}$, at $5000 \mathrm{~mm} / \mathrm{min}$ it is $0.28 \mathrm{~mm}$, at $5500 \mathrm{~mm} / \mathrm{min}$ it is $0.29 \mathrm{~mm}$ and at $6000 \mathrm{~mm} / \mathrm{min}$ it is $0.27 \mathrm{~mm}$. Result variation is the highest for $4000 \mathrm{~mm} / \mathrm{min}$ and $5500 \mathrm{~mm} / \mathrm{min}$ cases. Box plots of surface roughness by cutting speed (Fig. 9) reveal a normal result point distribution for the $3000 \mathrm{~mm} / \mathrm{min}$ and the $4500 \mathrm{~mm} / \mathrm{min}$ case and a close to normal result point distribution for the $3500 \mathrm{~mm} / \mathrm{min}$ case with a denser result point distribution towards lower than median. At cutting speed $4000 \mathrm{~mm} / \mathrm{min}$ result points are distributed only in the direction towards higher than median. At cutting speed $5000 \mathrm{~mm} / \mathrm{min}$ and at $5500 \mathrm{~mm} / \mathrm{min}$ only two result points are available and at cutting speed $6000 \mathrm{~mm} / \mathrm{min}$ only one result point is available. Surface roughness mean value at cutting speed $3000 \mathrm{~mm} / \mathrm{min}$ is $7.75 \mu \mathrm{m}$, at $3500 \mathrm{~mm} / \mathrm{min}$ it is $7.67 \mu \mathrm{m}$, at $4000 \mathrm{~mm} / \mathrm{min}$ it is $6.927 \mu \mathrm{m}$, at $4500 \mathrm{~mm} / \mathrm{min}$ it is $6.14 \mu \mathrm{m}$, at $5000 \mathrm{~mm} / \mathrm{min}$ it is $6.57 \mu \mathrm{m}$, at $5500 \mathrm{~mm} / \mathrm{min}$ it is $5.23 \mu \mathrm{m}$ and at cutting speed $6000 \mathrm{~mm} / \mathrm{min}$ it is $3.73 \mu \mathrm{m}$. Result variation is the highest for $5500 \mathrm{~mm} / \mathrm{min}$ case.

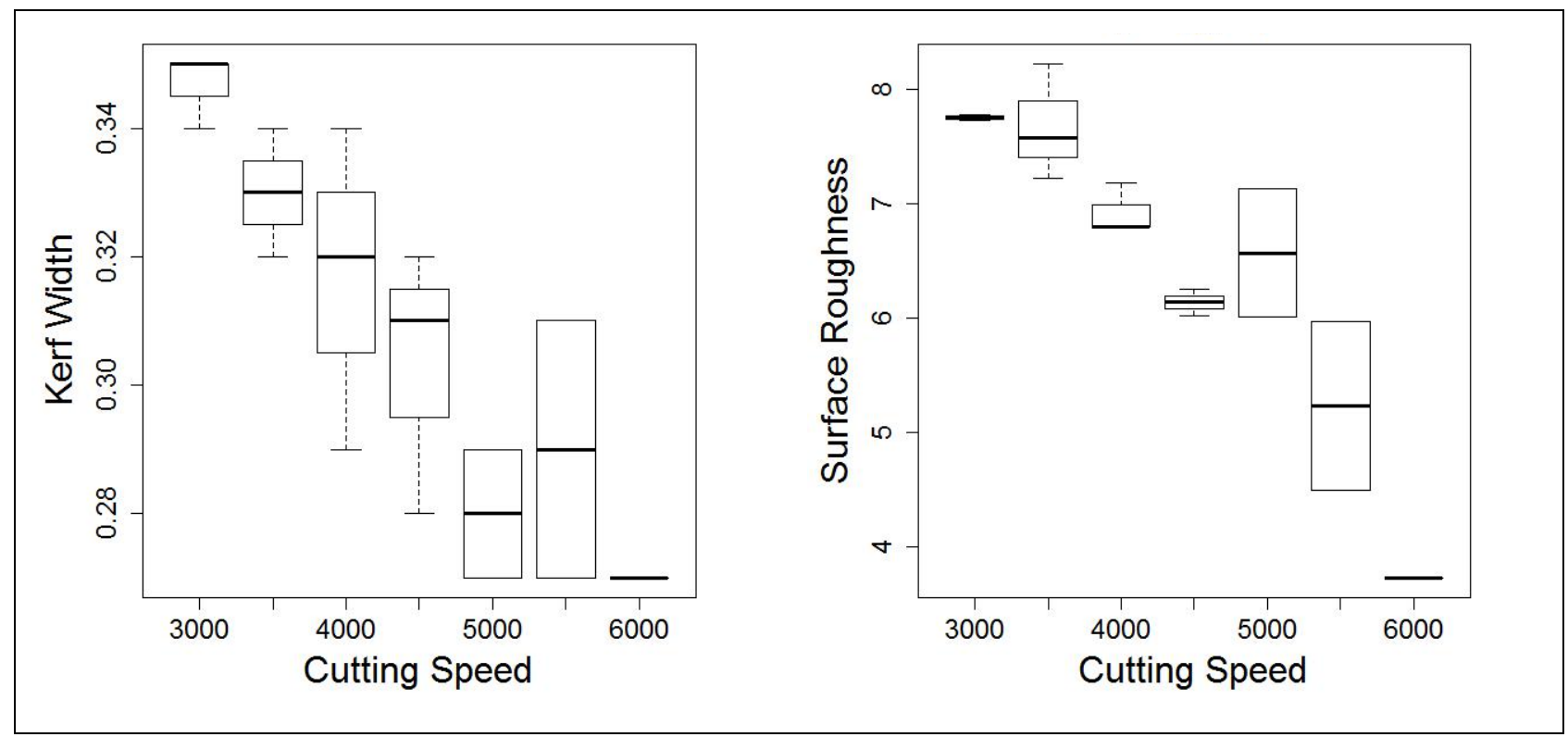

Fig. 9. Box plots for kerf width (left) and surface roughness (right) by speed - oxygen.

Box plot of kerf width (Fig. 10) at laser power $1500 \mathrm{~W}$ reveals a close to normal result point distribution with a wider range in the direction towards higher kerf width values. At laser power $1750 \mathrm{~W}$ the distribution is close to normal with one outliner point below the first quartile line. At laser power $2000 \mathrm{~W}$ the measured kerf width result distribution is completely symmetrical. At $1750 \mathrm{~W}$ laser power the mean value is the highest at $0.32 \mathrm{~mm}$. For $1500 \mathrm{~W}$ and $2000 \mathrm{~W}$ the mean value is $0.31 \mathrm{~mm}$. Result point variation is highest for $2000 \mathrm{~W}$ case. Box plot of surface roughness by laser power reveals a close to normal result point distribution for each individual power level, (Fig. 10). At laser power $1500 \mathrm{~W}$ and $2000 \mathrm{~W}$ a wider result point distribution range in the direction of smaller than median is revealed and at $1750 \mathrm{~W}$ a wider result point distribution range in the direction of higher than median is revealed. Surface roughness mean values are $7.04 \mu \mathrm{m}$ at $1500 \mathrm{~W}, 7.03 \mu \mathrm{m}$ at $1750 \mathrm{~W}$ and $6.07 \mu \mathrm{m}$ at $2000 \mathrm{~W}$. Result point variation is highest for $2000 \mathrm{~W}$ case. 

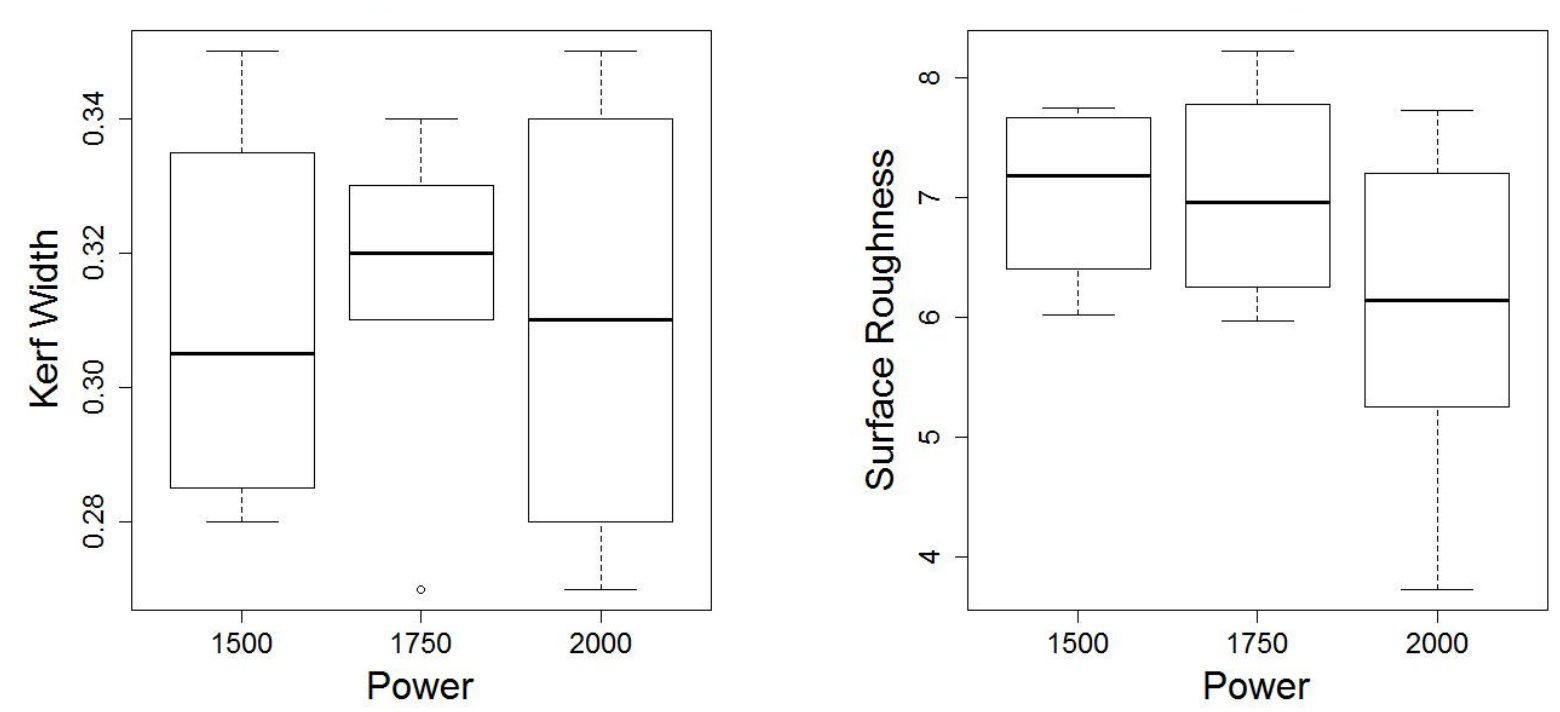

Fig. 10. Box plots for kerf width (left) and surface roughness (right) by power-oxygen.

\subsection{Nitrogen as assist gas}

In statistical analysis 10 experiments are available for nitrogen as assist gas. Cutting speed measurement range is $1000 \mathrm{~mm} / \mathrm{min}$ to $2250 \mathrm{~mm} / \mathrm{min}$ and laser power measurement range is $1500 \mathrm{~W}$ to $2000 \mathrm{~W}$. Number of available result points for each cutting speed and each laser power is visible in Table 5. Minimum and maximum measured values for kerf width and surface roughness as well as median, mean and first and third quartile values are also visible in Table 5.

\begin{tabular}{|c|c|c|c|c|c|c|c|}
\hline \multicolumn{2}{|c|}{ Cutting Speed } & \multicolumn{2}{c|}{ Power } & \multicolumn{2}{c|}{ Kerf Width } & \multicolumn{2}{c|}{ Surface Roughness } \\
\hline$[\mathrm{mm} / \mathrm{min}]$ & $\begin{array}{c}\text { Result } \\
\text { points }\end{array}$ & {$[\mathrm{W}]$} & $\begin{array}{c}\text { Result } \\
\text { points }\end{array}$ & Value & {$[\mathrm{mm}]$} & Value & {$[\mu \mathrm{m}]$} \\
\hline 1000 & 3 & 1500 & 3 & Min. & 0.170 & Min. & 4.970 \\
\hline 1500 & 3 & 1750 & 3 & 1st Quartile & 0.180 & 1st Quartile & 5.410 \\
\hline 2000 & 3 & 2000 & 4 & Median & 0.190 & Median & 5.695 \\
\hline 2250 & 1 & & & Mean & 0.187 & Mean & 5.836 \\
\hline & & & & 3rd Quartile & 0.190 & 3rd Quartile & 6.152 \\
\hline & & & & Max. & 0.200 & Max. & 7.140 \\
\hline
\end{tabular}

Tab. 5. Summary of measurement data analysis for nitrogen.

Measurement result frequency of kerf width (Fig. 11) is highest in range from $0.185 \mathrm{~mm}$ to $0.19 \mathrm{~mm}$ with four available result points, followed by range interval from $0.175 \mathrm{~mm}$ to $0.18 \mathrm{~mm}$ with three result points, $0.195 \mathrm{~mm}$ to $0.2 \mathrm{~mm}$ with two results points and $0.17 \mathrm{~mm}$ to $0.175 \mathrm{~mm}$ with one result point. In range from $0.18 \mathrm{~mm}$ to $0.185 \mathrm{~mm}$ and $0.19 \mathrm{~mm}$ to $0.195 \mathrm{~mm}$ no result points are available. Measurement result frequency of surface roughness (Fig. 11) is highest in range from $5 \mu \mathrm{m}$ to $5.5 \mu \mathrm{m}$ and from $5.5 \mu \mathrm{m}$ to $6 \mu \mathrm{m}$ with three available result points. One result point is available in each of the remaining range intervals. 

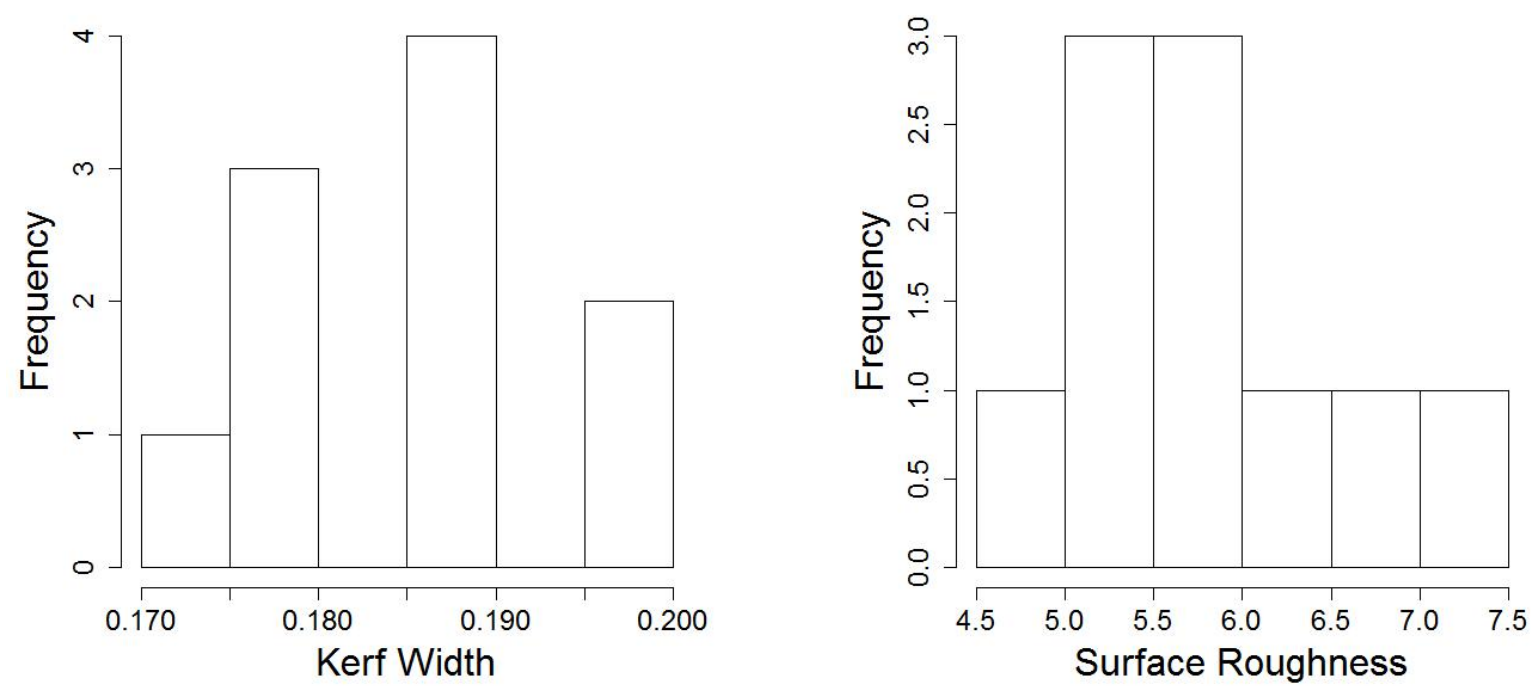

Fig. 11. Histogram for kerf width (left) and surface roughness (right) - nitrogen.

A weak match between kerf width measurement results and a normal distribution is revealed in the Q-Q normal plot graph (Fig. 12). Kerf width results are distributed on four levels. Deviations from normal line are found on all levels. A weak match between surface roughness measurement results and a normal distribution is revealed in the Q-Q normal plot graph (Fig. 12). Bigger deviations are found at the high end of the graph.
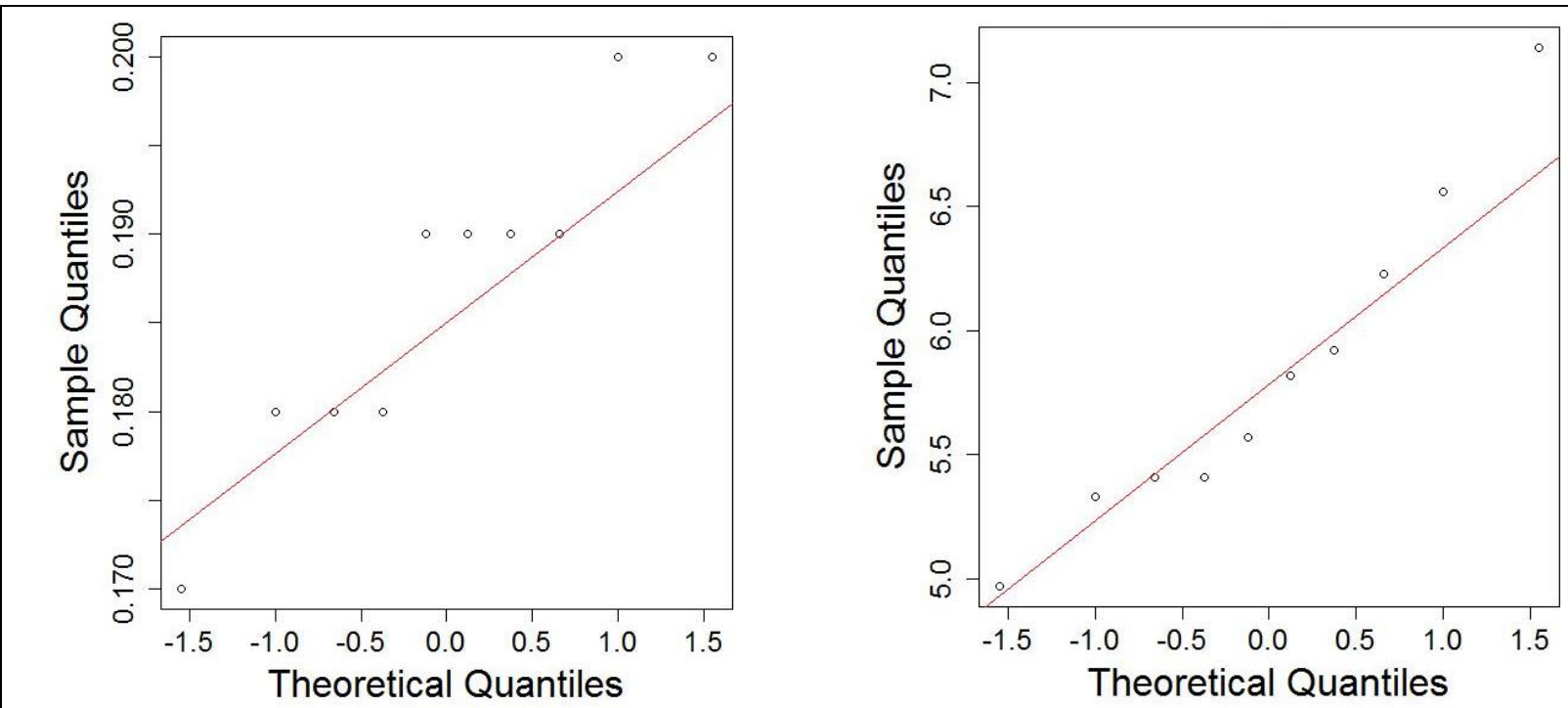

Fig. 12. Normal Q-Q plot for kerf width (left) and surface roughness (right) - nitrogen.

Box plot of all measured kerf width results reveals a wider result point variation range towards smaller then median kerf width values (Fig. 13). In the direction higher than median only whiskers points exist. A mean value of $0.19 \mathrm{~mm}$ is found. Box plot of all measured surface roughness results reveals a wider result point variation range towards higher than median values (Fig. 13). A mean surface roughness value of $5.84 \mu \mathrm{m}$ is found. 

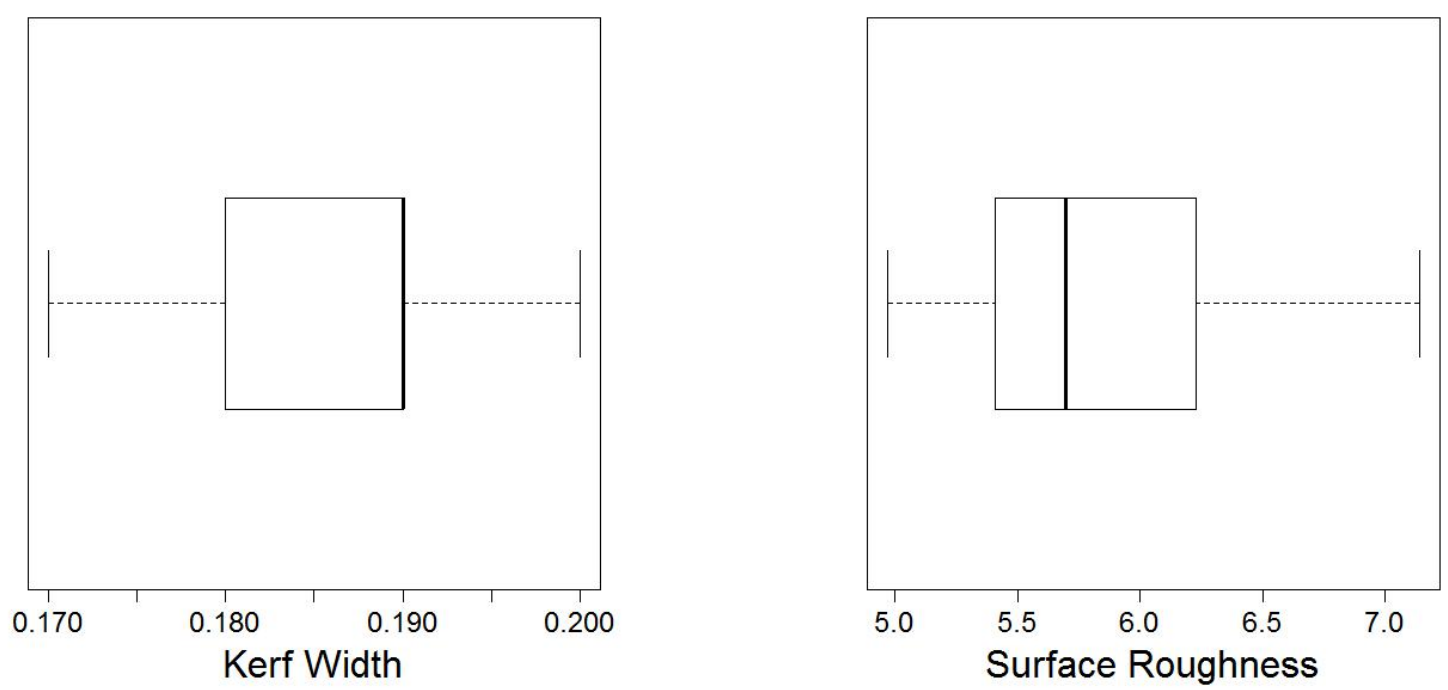

Fig. 13. Box plots of overall kerf width (left) and surface roughness (right) - nitrogen.
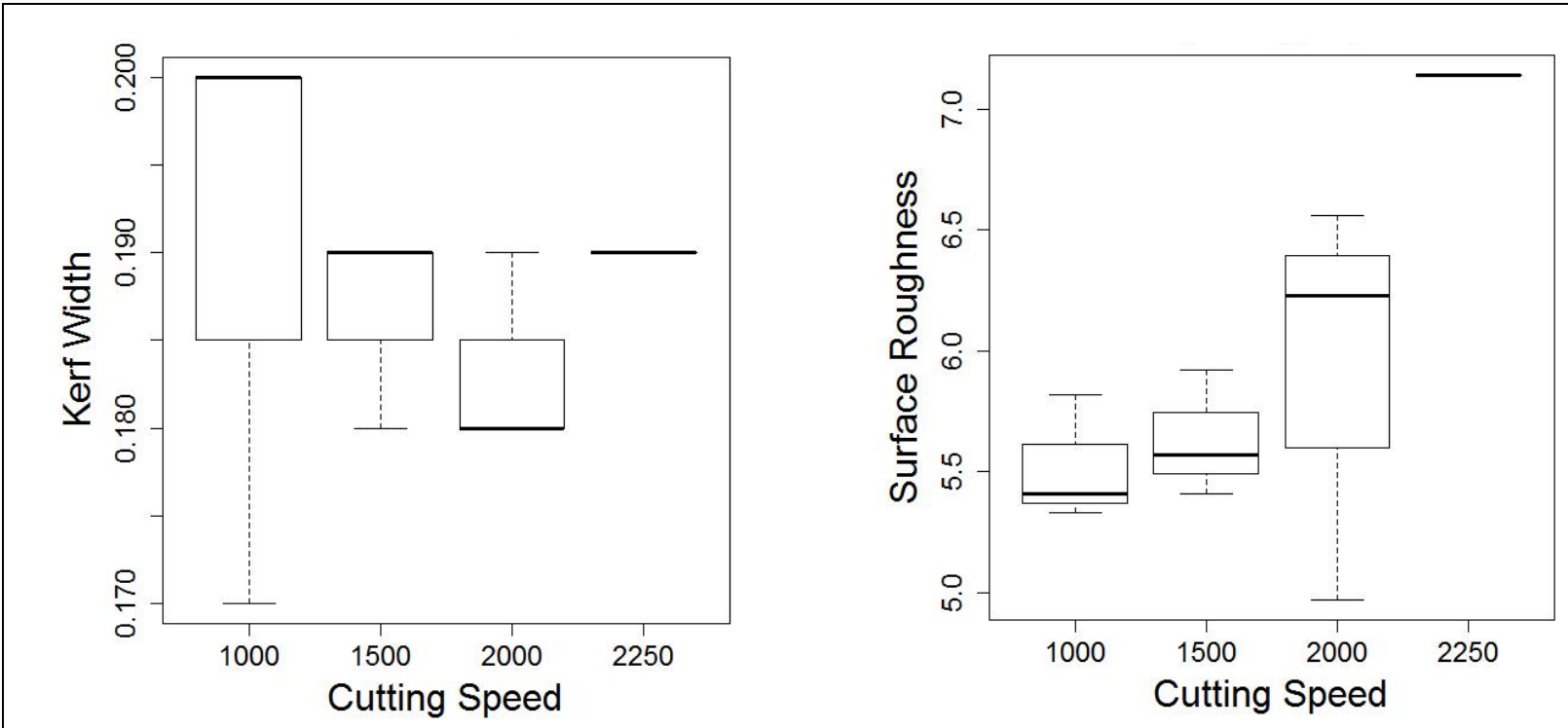

Fig. 14. Box plots for kerf width (left) and surface roughness (right) by speed-nitrogen.

Box plots of kerf width by cutting speed (Fig. 14) reveal an unbalanced result point distribution for all cases. For $1000 \mathrm{~mm} / \mathrm{min}$ result variation is the highest and oriented only towards lower than median values. Mean kerf width at $1000 \mathrm{~mm} / \mathrm{min}$ is $0.19 \mathrm{~mm}$. At $1500 \mathrm{~mm} / \mathrm{min}$ result point distribution is found only towards lower than median kerf width values. Mean kerf width value at $1500 \mathrm{~mm} / \mathrm{min}$ is $0.19 \mathrm{~mm}$. At 2000 $\mathrm{mm} / \mathrm{min}$ result point variation range is similar to $1500 \mathrm{~mm} / \mathrm{min}$, while result point distribution is found only in direction towards higher than median values. Mean kerf width value at $2000 \mathrm{~mm} / \mathrm{min}$ is $0.18 \mathrm{~mm}$. At cutting speed $2250 \mathrm{~mm} / \mathrm{min}$ only one result point is available with mean kerf width value $0.19 \mathrm{~mm}$. Box plots of surface roughness by cutting speed (Fig. 14) for $1000 \mathrm{~mm} / \mathrm{min}$ and $1500 \mathrm{~mm} / \mathrm{min}$ cases reveal a wider result point distribution towards higher than median values. At $2000 \mathrm{~mm} / \mathrm{min}$ the result point distribution range is wider towards lower than median values. Result 
point variation at $2000 \mathrm{~mm} / \mathrm{min}$ is the highest among all cases. At $2250 \mathrm{~mm} / \mathrm{min}$ one point is measured. Mean surface roughness values are $5.52 \mu \mathrm{m}$ at $1000 \mathrm{~mm} / \mathrm{min}$, $5.63 \mu \mathrm{m}$ at $1500 \mathrm{~mm} / \mathrm{min}, 5.92 \mu \mathrm{m}$ at $2000 \mathrm{~mm} / \mathrm{min}$ and 7.14 at $2250 \mathrm{~mm} / \mathrm{min}$.

Kerf width by power box plots revel a normal result point distribution at all laser power levels (Fig. 15). Mean values are $0.18 \mathrm{~mm}$ at $1500 \mathrm{~W}$ and $0.19 \mathrm{~mm}$ at $1750 \mathrm{~W}$ and $2000 \mathrm{~W}$. Surface roughness by power box plots (Fig. 15) reveal a normal result point distribution for $1500 \mathrm{~W}$ and $2000 \mathrm{~W}$ cases and a more dense result point distribution in the direction towards lower than median for the $1750 \mathrm{~W}$ case.

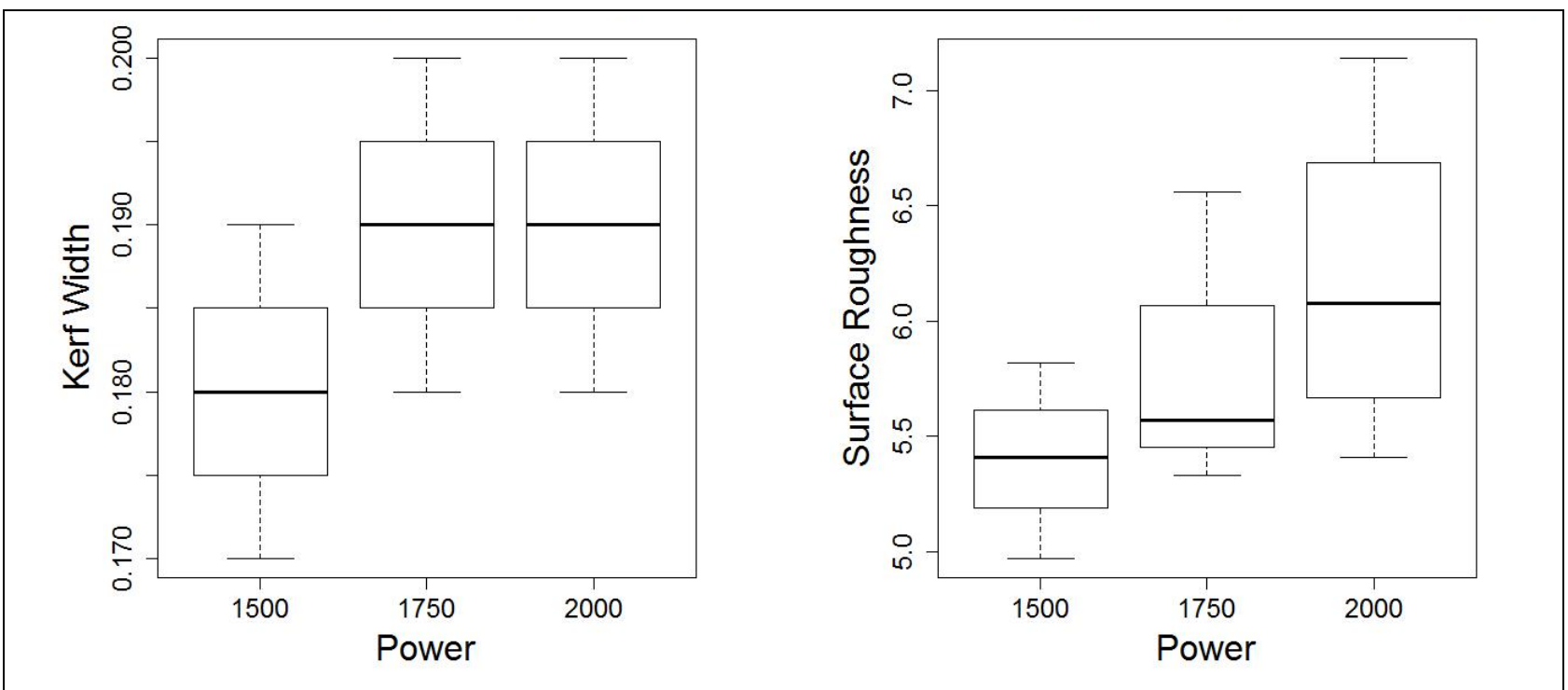

Fig. 15. Box plots for kerf width (left) and surface roughness (right) by power-nitrogen.

\subsection{Summary results}

When using air as assist gas a weak reduction of kerf width with rising cutting speed is observed. With oxygen assist gas a kerf width reduction with rising cutting speed is found, with an exception point at $5000 \mathrm{~mm} / \mathrm{min}$. As only a few result points are available at $5000 \mathrm{~mm} / \mathrm{min}$ and at higher cutting speeds and if considering the extreme values for those cases, the observed trend can be generalized over the complete cutting speed range. With nitrogen as assist gas, kerf width mean values are falling with rising cutting speed in range from $1000 \mathrm{~mm} / \mathrm{min}$ to $2000 \mathrm{~mm} / \mathrm{min}$. As only one result point is available at $2250 \mathrm{~mm} / \mathrm{min}$, the trend can be extrapolated over the complete cutting speed range. Generally, by rising cutting speed a reduction of kerf width can be expected regardless of assist gas type.

When using air as assist gas no clear trend is observed between $2500 \mathrm{~mm} / \mathrm{min}$ and $4000 \mathrm{~mm} / \mathrm{min}$. In this interval, surface roughness result points range from $3 \mu \mathrm{m}$ to 4 $\mu \mathrm{m}$. At $2000 \mathrm{~mm} / \mathrm{min}$, surface roughness mean value is $50 \%$ higher than mean values in range from $2500 \mathrm{~mm} / \mathrm{min}$ to $4000 \mathrm{~mm} / \mathrm{min}$ and at cutting speed $6000 \mathrm{~mm} / \mathrm{min}$ it is $25 \%$ lower, resulting in a general trend of lower surface roughness towards higher cutting speeds. With oxygen as assist gas a trend of surface roughness reduction by rising cutting speed is observed. Similar to kerf width an exception point is detected at 
cutting speed $5000 \mathrm{~mm} / \mathrm{min}$. When nitrogen is used as assist gas, a trend of rising surface roughness by rising cutting speed is detected, but also result point variation is rising with rising cutting speed. The first is different to air and oxygen cases. It is found that, surface roughness by cutting speed trend is dependent on assist gas type.

Almost no effect of laser power on kerf width is detected when using air as assist gas. When oxygen is used, maximum mean kerf width value is found at $1750 \mathrm{~W}$. A weak kerf width rise by rising laser power over the complete range is detected. If nitrogen is used as assist gas, minimum mean kerf width value is found at $1500 \mathrm{~W}$. At higher laser power kerf width is constant. Overall, small differences in kerf width are detected and a minor effect of laser power on kerf width is concluded. Generally, with rising laser power a rising kerf width is to be expected.

When using air as assist gas, with rising laser power a rising surface roughness is detected. When using oxygen, a falling surface roughness by rising power is detected. When using nitrogen, a rising surface roughness by rising laser power is detected, but also result point variation is rising with rising power. It is found, that surface roughness by power trend is dependent on assist gas type.

\section{Contour plots}

To present trends over complete measurement range for both process parameters, contour plots are generated. One plot is generated for each result parameter and each assist gas. A fitting model considering main effects and factor interactions is selected and applied on the complete air, oxygen and nitrogen data sets. Fig. 16 relates to the contour plots for kerf width on the left hand side and for surface roughness on the right hand side.

For air, cutting speed has a stronger effect on kerf width than power, while for oxygen or nitrogen power has a stronger effect. For air and oxygen, lowest kerf width values are found at highest cutting speeds and at lowest laser powers. For nitrogen, lowest kerf width values are found at lowest cutting speeds and at lowest powers. In case of nitrogen, if both parameters are rising, kerf width passes a maximum in the middle of the measurement range. At lower cutting speeds for nitrogen, power has a stronger effect on kerf width, while at higher powers, cutting speed has a stronger effect on kerf width.

In case of air or oxygen, power has a stronger effect on surface roughness than cutting speed, while cutting speed has a stronger effect if nitrogen is used. The lowest surface roughness values for air are found at highest cutting speeds and at lowest powers, for oxygen at highest cutting speeds and at highest powers and for nitrogen at highest cutting speeds and lowest powers and at lowest cutting speeds and highest powers. In case of nitrogen, if both parameters are rising, surface roughness passes a local minimum. 
Gotlih, J.; Klancnik, S.; Begic-Hajdarevic, D.; Ficko, M.; Cekic, A.; Balic, J. \& Co...

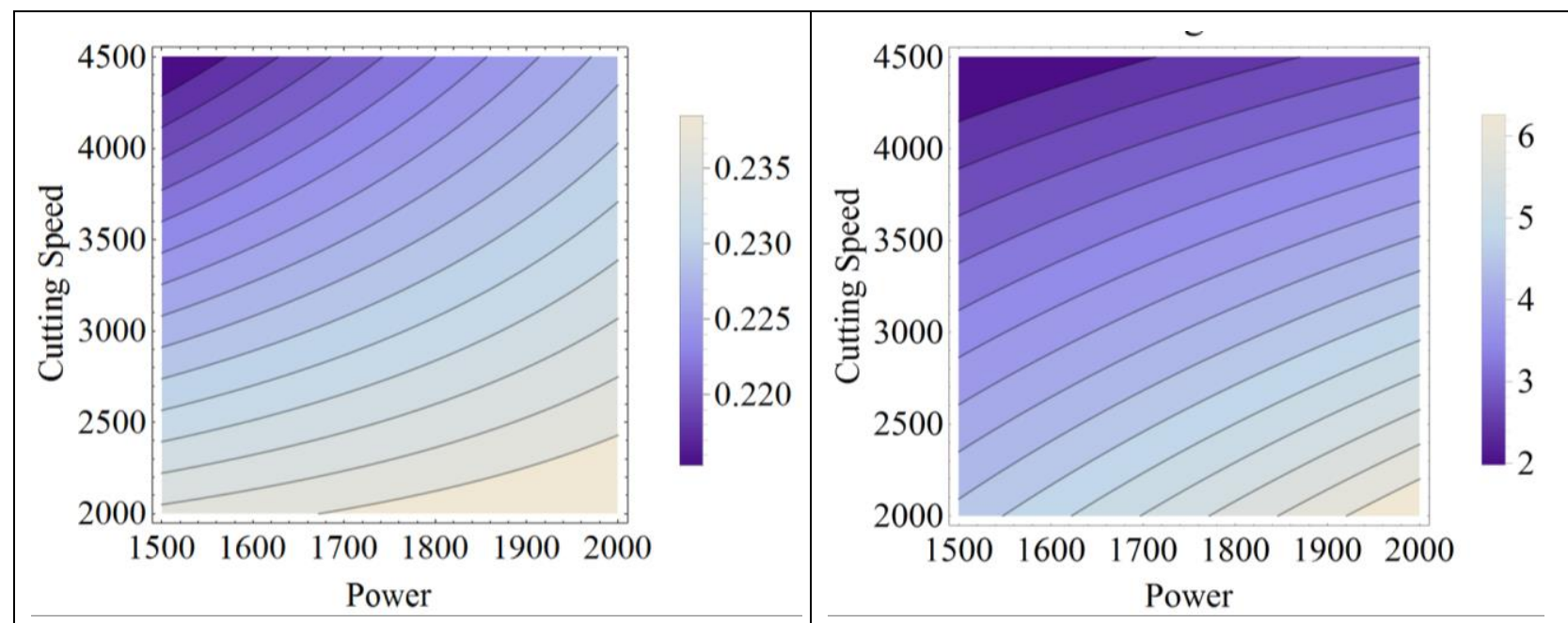

a) Air as assist gas - kerf width

a) Air as assist gas - surface roughness
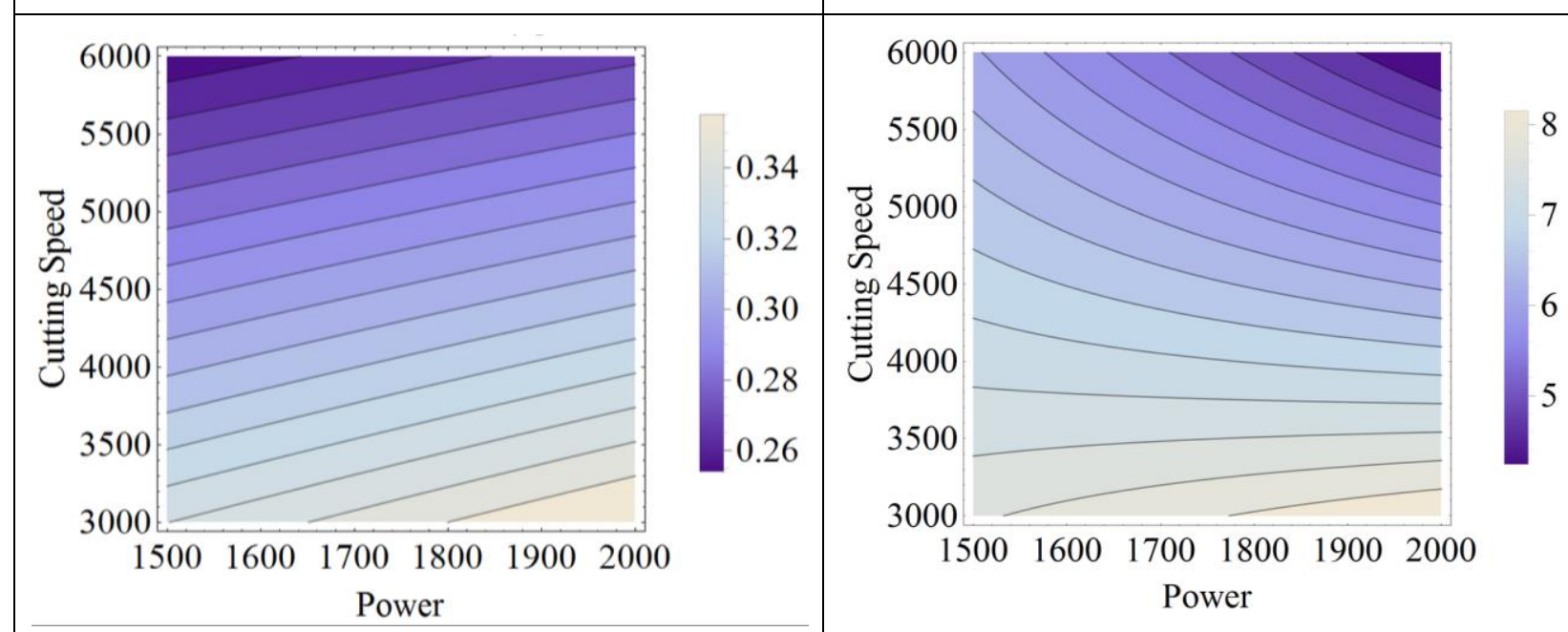

b) Oxygen as assist gas - kerf width

b) Oxygen as assist gas - surface roughness

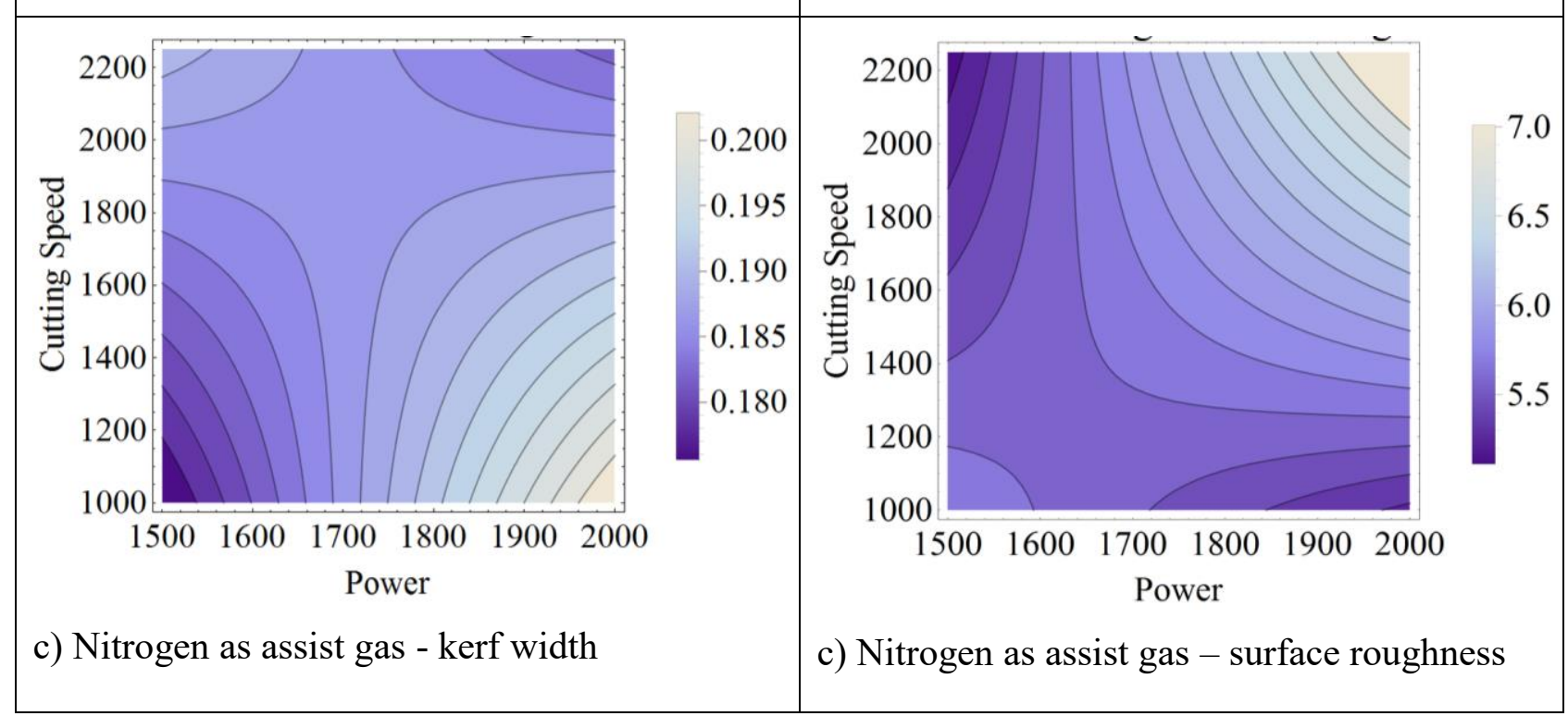

Fig. 16. Contour plots for kerf width (left) and surface roughness (right). 


\section{Conclusion}

The analysis shows that the quality of the cut region is dependent on all considered parameters and that it is affected differently if the same process parameter trends, but different assist gases are used. Surface roughness by cutting speed and surface roughness by power trends are found to be dependent on assist gas choice. For the kerf width quality criteria no similar behavior was observed. A general conclusion can be made that regardless of assist gas, kerf width is rising with rising cutting speed or with rising laser power. By rising both parameters, kerf width is rising, with a minor exception detected for nitrogen at the highest measured parameter values.

Due to the use of different measurement intervals for each assist gas type and the low amount of data in some regions, the results are not the most suitable for comparison. As a consequence, the analysis does not try to result in a general conclusion, but rather offers individual interpretations of process behavior for a better understanding of the laser cutting technology.

In the future work, more detailed discussions should be considered on the impact of different process parameters and type material on the quality characteristics in some non-conventional cutting processes such as abrasive water jet cutting, plasma arc cutting and so on.

\section{Acknowledgements}

The authors acknowledge the project (Non-conventional machining processes: Optimization of process parameters using artificial intelligence, BI-BA/1617-034) was financially supported by the Slovenian Research Agency and the Federal Ministry of Education and Science, Bosnia and Herzegovina.

\section{References}

Adalarasan, A.; Santhanakumar, M. \& Rajmohan, M. (2015). Optimization of laser cutting parameters for A16061/SiCp/Al2O3 composite using grey based response surface methodology (GRSM). Measurement, 73, (596-606), ISSN: 0263-2241

Begic-Hajdarevic, D. \& Bijelonja, I. (2014). Experimental and numerical investigation of temperature distribution and hole geometry during laser drilling process. Procedia Engineering, 100, (384-393), ISSN: 1877-7058

Begic-Hajdarevic, D.; Pasic, M.; Vucijak, B. \& Cekic, A. (2016). Statistical process control of surface roughness during $\mathrm{CO}_{2}$ laser cutting using oxygen as assist gas, Proceedings of the 26th DAAAM International Symposium, Katalinic, B. (Ed.), pp.0247-0255, ISBN 978-3-902734-07-5, Zadar, October 2015, DAAAM International, Vienna, Austria

Eltawahni, H.A.; Benyounis, K.Y. \& Olabi, A.G. (2016). High Power CO2 Laser Cutting for Advanced Materials - Review, In: Reference Module in Materials Science and Materials Engineering, pp. (1-27), Elsevier, ISBN: 978-0-12-803581-8 
Eltawahni, H.A.; Hagino, M.; Benyounis, K.Y.; Inoue, T. \& Olabi, A.G. (2012). Effect of $\mathrm{CO} 2$ laser cutting process parameters on edge quality and operating cost of AISI316L. Optics \& Laser Technology, 44, (1068-1082), ISSN: 0030-3992

Ficko, M. \& Palcic, I. (2013). Designing a layout using the modified triangle method, and genetic algorithms. International Journal of Simulation Modelling, 12, 4, (237251), ISSN: 1726-4529

Ghany, K. A. \& Newishy, M. (2005). Cutting of $1.2 \mathrm{~mm}$ thick austenitic stainless steel sheet using pulsed and CW Nd:YAG laser. Journal of Materials Processing Technology, 168, (438-447), ISSN: 0924-0136

Kadri, B.M.; Nisar, S.; Khan, Z.S. \& Khan, A.W. (2015). Comparison of ANN and finite element model for the prediction of thermal stresses in diode laser cutting of float glass. Optik - International Journal for Light and Electron Optics, 126, 19, (19591964), ISSN: 0030-4026

Klancnik, S.; Begic-Hajdarevic, D.; Paulic, M.; Ficko, M.; Cekic, A. \& Cohodar Husic, M. (2015). Prediction of Laser Cut Quality for Tungsten Alloy Using the Neural Network Method. Strojniški vestnik - Journal of Mechanical Engineering, 61, 12, (714720), ISSN: 0039-2480

Klancnik, S.; Brezocnik, M. \& Balic, J. (2016). Intelligent CAD/CAM System for Programming of CNC Machine Tools. International Journal of Simulation Modelling, 15, 1, (109-120), ISSN: 1726-4529

Mohamed, Omar A.; Masood, Syed H. \& Bhowmik Jahar L. (2016). Investigation of dynamic elastic deformation of parts processed by fused deposition modeling additive manufacturing. Advances in Production Engineering \& Management, 11, 3, (227-238), ISSN: $1854-6250$

Pandey, K.A. \& Dubey, K.A. (2012). Taguchi based fuzzy logic optimization of multiple quality characteristics in laser cutting of Duralumin sheet. Optics and Lasers in Engineering, 50, (328-335), ISSN: 0143-8166

Rao, R.V.; Rai, D.P.; Ramkumar, J. \& Balic, J. (2016). A new multi-objective Jaya algorithm for optimization of modern machining processes. Advances in Production Engineering \& Management, 11, 4, (271-286), ISSN: 1854-6250

Rodic, D.; Gostimirovic, M.; Kovac, P.; Radovanovic, M. \& Savkovic, B. (2014). Comparison of fuzzy logic and neural network for modelling surface roughness in edm. International Journal of Recent Advances in Mechanical Engineering, 3, 3, (69-78), ISSN: 2200-5854

Saenz, C.D.; Castillo, G.N.; Romeva, C.R. \& Macia, L.J. (2015). A fuzzy approach for the selection of non-traditional sheet metal cutting processes. Expert Systems with Applications, 42, 15-16, (6147-6154), ISSN: 0957-4174

Saric T., Simunovic G., Simunovic K., Svalina I. (2016). Estimation of Machining Time for CNC Manufacturing Using Neural Computing. International Journal of Simulation Modelling, 15, 4, (663-675), ISSN: 1726-4529 